\title{
The roles of stress-activated Sty1 and Gcn2 kinases and proto- oncoprotein homologue Int6/elF3e in responses to endogenous oxidative stress during histidine starvation
}

\author{
Naoki Nemoto ${ }^{1,{ }^{*}}$, Tsuyoshi Udagawa ${ }^{1,{ }^{*},}$, Takahiro Ohira ${ }^{1,{ }^{*}, \text { Li Jiang }}{ }^{2}$, Kouji Hirota $^{3}$, Caroline \\ R. M. Wilkinson ${ }^{4}$, Jürg Bähler ${ }^{5}$, Nic Jones ${ }^{4}$, Kunihiro Ohta ${ }^{6}$, Ronald C. Wek ${ }^{2, \%}$, and Katsura \\ Asano ${ }^{1, \%}$ \\ ${ }^{1}$ Molecular Cellular and Developmental Biology Program, Division of Biology, Kansas State \\ University, Manhattan, KS 66506, USA \\ ${ }^{2}$ Department of Biochemistry and Molecular Biology, Indiana University School of Medicine, \\ Indianapolis, IN 46202, USA \\ ${ }^{3}$ Shibata distinguished scientist laboratory, RIKEN, Hirosawa 2-1, Wako-shi, Saitama 351-0198, \\ Japan \\ ${ }^{4}$ Cancer Research UK Cell Regulation Laboratory, Paterson Institute for Cancer Research, \\ University of Manchester, Manchester M20 4BX, UK \\ ${ }^{5}$ Department of Genetics, Evolution \& Environment and UCL Cancer Institute, University College \\ London, London WC1E 6BT, UK \\ ${ }^{6}$ Department of Life Sciences, Graduated School of Arts and Sciences, University of Tokyo, \\ Komaba 3-8-1, Meguroku, Tokyo 153-8902, JAPAN
}

\section{Abstract \\ In fission yeast, Sty1 and Gcn2 are important protein kinases regulating gene expression in response to amino acid starvation. The translation factor subunit eIF3e/Int6 promotes the Sty1- dependent response by increasing the abundance of Atf1, a transcription factor targeted by Sty 1 . While Gcn2 promotes expression of amino acid biosynthesis enzymes, the mechanism and function for Sty 1 activation and Int6/eIF3e involvement during this nutrient stress is not understood. Here we show that mutants lacking $s t y 1^{+}$or $g c n 2^{+}$display reduced viabilities during histidine depletion stress in a manner suppressible by the antioxidant, $\mathrm{N}$-acetyl cysteine, suggesting that these protein kinases function to alleviate endogenous oxidative damage generated during nutrient starvation. Int6/eIF3e also promotes cell viability by a mechanism involving}

\footnotetext{
() 2010 Elsevier Ltd. All rights reserved.

\%Address correspondence to: Katsura Asano, Molecular Cellular and Developmental Biology Program, Division of Biology, Kansas State University, Manhattan, KS 66506, USA; Phone 785532 0116; FAX 785532 6653; kasano@ksu.edu; Ronald C. Wek, Department of Biochemistry and Molecular Biology, Indiana University School of Medicine, Indianapolis, IN 46202, USA; rwek@iupui.edu. equal contribution

Publisher's Disclaimer: This is a PDF file of an unedited manuscript that has been accepted for publication. As a service to our customers we are providing this early version of the manuscript. The manuscript will undergo copyediting, typesetting, and review of the resulting proof before it is published in its final citable form. Please note that during the production process errors may be discovered which could affect the content, and all legal disclaimers that apply to the journal pertain.
} 
stimulation of the Sty1 response to oxidative damage. In further support of these observations, microarray data suggests that, during histidine starvation, int $6 \Delta$ increases the duration of Sty1activated gene expression linked to oxidative stress due to the initial attenuation of Sty1-dependent transcription. Moreover, loss of $g c n 2$ induces the expression of a new set of genes not activated in wild-type cells starved for histidine. These genes encode heatshock proteins, redox enzymes and proteins involved in mitochondrial maintenance, in agreement with the idea that oxidative stress is imposed onto gcn $2 \Delta$ cells. Furthermore, the early Sty 1 activation promotes a rapid Gen2 activation on histidine starvation. These results suggest that Gcn2, Sty1, and Int6/eIF3e are functionally integrated and cooperate to respond to oxidative stress that is generated during histidine starvation.

Translation initiation is an important target of stress responsive pathways regulated by various physiological and environmental signals. Reduced translation allows cells to conserve energy coincident with an altered programme of gene expression which leads to the production of proteins that have the capacity to ameliorate stress-induced damage ${ }^{1}$. Genetic alteration of eukaryotic translation initiation factors (eIFs) can disrupt the appropriate responses to physiological signals and stresses, which can alter the etiology and treatment of many diseases, including cancer ${ }^{2}$.

One of the key factors contributing to the onset of disease processes is oxidative stress, resulting from changes in metabolic activities or environmental stress ${ }^{3}$. Malignant tumorigenesis can involve the altered activities of eIF2a kinases (eIF2Ks), which is thought to provide cancer cells with increased resistance to nutritional and hypoxic stresses $4 ; 5$. Activation of eIF2Ks not only represses global protein synthesis, but preferentially enhances translation of key transcription factors, such as ATF4. ATF4 triggers the transcription of stress-related genes as part of the integrated stress response (ISR) and is involved in alleviating oxidative stress and in controlling nutrient uptake and metabolism, as well as apoptosis $6 ; 7 ; 8$. The eIF2Ks are conserved throughout eukaryotes. The unicellular model organism, Schizosaccharomyces pombe, encodes three of the conserved eIF2Ks, Gcn2, Hri1 and Hri2, each of which is implicated in the response to oxidative stress $9 ; 10$. Similar to the mammalian ISR, eIF2K activation in S. pombe and another yeast, Saccharomyces cerevisiae, promotes transcription of a common set of genes termed the general amino acid control response (GAAC) ${ }^{11 ; 12}$.

In conjunction with eIF2Ks, evolutionarily conserved stress-activated mitogen-activated protein kinases (MAPKs), including S. pombe Sty1 (also known as Spc1 or Phh1), also respond to oxidative stress. Sty1 is activated via a conserved MAPK cascade, including the MAPK kinase (MAP2K) Wis1 and the MAP2K kinases (MAP3K) Wis4 and Win1 ${ }^{13}$. Sty1 activation then leads to the enhanced stability of the Atf1 transcription factor via mechanisms involving Atf1 phosphorylation and increased Atf1 activity via a phosphorylation-independent process ${ }^{14 ; 15}$. As a consequence, oxidative stress triggers the expression of a group of genes termed the core environmental stress response (CESR), most of which are dependent upon the Sty1/Atf1 pathway ${ }^{16}$.

We recently found that both Sty 1 and Gcn2 protein kinases are required for the response of S. pombe to histidine starvation elicited by the drug 3-aminotriazole (3AT), and that Gcn2 
facilitates increased transcription of genes encoding amino acid biosynthetic enzymes in response to the nutritional deficiency ${ }^{12}$. While the Sty1 MAPK pathway has been linked to oxidative, osmotic and DNA-damaging conditions ${ }^{16}$, activation of Sty1 in the response to histidine starvation was somewhat surprising, given that amino acid starvation is not thought to cause oxidative damage and that Sty1 does not facilitate transcription of amino acid biosynthetic genes ${ }^{12}$.

Interestingly, the Sty1-dependent response during nutrient starvation is promoted by Int6/ eIF3e ${ }^{12}$, whose mammalian homologue is encoded by a frequent integration site of mouse mammary tumor virus (MMTV) termed int $-6^{17}$. int- 6 encodes the e-subunit of eIF3 ${ }^{18}$. Mammalian eIF3 is composed of 13 subunits (eIF3a-m), and serves as the scaffold for eIF2 and the cap binding protein, eIF4F, which assists binding of the $40 \mathrm{~S}$ ribosome to mRNA ${ }^{19}$. Although truncated forms of Int-6/eIF3e found in MMTV-integrated tumors are known to be oncogenic both in vitro ${ }^{20 ; 21}$ and in vivo ${ }^{22}$, the mechanism of tumorigenesis caused by Int-6 misregulation remains elusive. $S$. pombe encodes 11 of the 13 subunits found in mammalian eIF3 $23 ; 24 ; 25$. int $6^{+}$is not essential in fission yeast, but its loss (int6 $\Delta$ ) reduces translation initiation in yeast cultured in minimal media ${ }^{12 ; 23}$. This finding is in agreement with the important roles of eIF3e in translation initiation in mammalian cells ${ }^{26 ; 27}$. S. pombe Int6/ eIF3e promotes the Sty1-dependent response at least in part by stimulating expression of atfl $1^{+}$by translational or posttranslational process ${ }^{12}$.

In this study, we explored the integration between the Sty1/Atf1 MAPK pathway and key translational regulators - eIF2Ks and Int6/eIF3e in the control of gene expression and cell viability during nutrient stress. Our results suggest that during histidine starvation, Sty1 and Gcn2 cooperate to alleviate endogenous oxidative damage, which might be generated by a change in the nutrient status. Furthermore, evidence is provided that Int6/eIF3e modulates the Sty1 response to oxidative damage. Our results support the model that alleviating oxidative damage during canonical nutritional stress is an important function of the integrated Sty1, Int6/eIF3e, and eIF2K stress response pathways. These findings provide insight into the cellular roles of eIF2Ks during nutrient deprivation, and provide clues to understanding the mechanism by which MMTV integration at the murine int- 6 locus can contribute to tumorigenesis.

\section{Results}

\section{Histidine starvation, as induced by 3AT, directly promotes Sty1-directed transcription}

3AT is a potent inhibitor of the histidine biosynthesis enzyme, imidazoleglycerol-phosphate dehydratase (encoded by $S$. pombe His5), causing histidine starvation in an otherwise prototrophic strain. Because 3AT is also suggested to inhibit other enzymes, such as catalase ${ }^{28}$, we wished to test if the CESR is induced specifically by histidine starvation. For this purpose, we treated cells with 3AT in the presence or absence of added histidine. We then measured accumulation of four representative CESR transcripts, atf $1^{+}, \mathrm{pcrl}^{+}, \mathrm{ctal} \mathrm{I}^{+}$ and $g p d 1^{+}$mRNAs by Northern blotting (Fig. 1). As described above, Atf1 is a basic leucine-zipper (bZIP) factor responsible for mediating many Sty1-dependent transcriptional events; Pcr1 is a second bZIP factor which forms heterodimers with Atf1 and is also




the major catalase activity induced by various Sty 1 -activating signals ${ }^{16}$; and Gpd1 is a glycerol-3-phosphate dehydrogenase, producing glycerol in response to osmotic stress ${ }^{31}$. The addition of histidine completely eliminated the accumulation of these four transcripts, which were induced with $30 \mathrm{mM}$ 3AT in wild-type cells (Fig. 1). Together with our previous finding that 3AT sensitivity of the styl mutant is completely alleviated by addition of histidine ${ }^{12}$, these results endorse the specific effect of 3AT on the His5 enzyme in this yeast, and further suggest that histidine starvation, rather than inhibition of catalase or other enzymes, directly promotes CESR transcription under 3AT-induced stress.

\section{Sty1 MAPK cascade, Gcn2, and Int6/elF3e appear to alleviate oxidative stress generated during 3AT-induced starvation}

In order to gain insight into the mechanism whereby Sty1 is activated by 3AT-induced histidine starvation, we examined the involvement of other components of the Sty1 MAPK signaling pathway (see Fig. 2A), which were previously linked with oxidative stress. Thus, we tested the 3AT-sensitivity of mutant strains defective for Wis1 MAP2K, Wis4/Win1 MAP3K, Mpr1/Mcs4 phosphorelay proteins, Mak1/Mak2/Mak3 histidine kinases ${ }^{13}$ and the glycolytic enzyme Tdh $1{ }^{32}$ (Fig. 2B and TO and KA, unpublished data). Among these mutants, those deleted for $m c s 4^{+}$, wis $1^{+}$or wis $4^{+}$were $3 \mathrm{AT}$-sensitive in a manner reversed by histidine (Fig. 2B). Therefore, a canonical MAPK cascade leading to Sty 1 activation is required for survival upon 3AT exposure, as illustrated in Fig. 2A.

Because a major function of the canonical Sty1 MAPK cascade is to ameliorate oxidative damage, we hypothesized that the 3AT-induced, Int6/eIF3e-assisted Sty1 pathway is also expressed to this end. In an effort to test this model, we used the antioxidant, $\mathrm{N}$-acetyl cysteine (NAC). As expected, NAC rescued the slow growth of the strains deleted for sty $1^{+}$or $i n t 6^{+}$in the presence of 3AT in a dilution assay (Fig. 2C, compare panels 2 and 3, rows 2 and 4). Likewise, NAC rescued the 3AT-sensitivity of the mutants deleted for $\mathrm{mcs}^{+}$, wis $1^{+}$or wis $4^{+}$(Fig. 2B). We previously showed that styl $1^{+}$and $i n t 6^{+}$do not simply increase expression of histidine biosynthesis enzymes ${ }^{12}$; otherwise NAC would not rescue 3AT sensitivity of the cells deleted for these genes. Thus, the 3AT sensitivities of the styl $1 \Delta$ and int $6 \Delta$ cells, and most likely those of other Sty 1 pathway mutants, could be due to a failure of these mutant strains to respond to endogenous oxidative stress that might accompany histidine starvation.

In light of these findings, we also examined if NAC rescues the 3AT sensitivity of $\operatorname{gcn} 2 \Delta$ cells, and to our surprise, we found that it did, albeit partially (Fig. 2C, lane 6). This suggests that $\mathrm{Gcn} 2$ functions to ameliorate oxidative damage. In order to test if the sensitivity of gcn $2 \Delta$ cells is due to a failure in Gcn2 phosphorylation of eIF2a, we tested the 3AT sensitivity of the mutant cells altering the eIF2a phosphorylation site, Ser-51, to alanine (sui2-S51A) ${ }^{33}$. The sui2-S51A strain is also 3AT-sensitive in a manner suppressible by NAC (Fig. 2C). These findings suggest that phosphorylation of eIF2a by Gen2 is also important for alleviating oxidative stress during amino acid starvation. 


\section{Sty1 MAPK suppresses cell death and genetic suppression during histidine starvation in a manner reversed by an antioxidant}

While the major biological function of NAC is as an antioxidant, NAC or its cellular product, reduced glutathione, has other biological functions. To address if NAC rescues the 3AT sensitivity of tested mutants by ameliorating cellular (oxidative) damage, we examined whether 3AT directly reduces the viability of the mutant cells, and if so, whether NAC reverses this effect. For this purpose, we grew yeast in semi-exponential phase for several days by successive inoculation into fresh media in the presence or absence of 3AT (Fig. S1), and quantified cell viability at different times.

We first measured the survival of the wild-type and sty $1 \Delta$ cells following culturing for 1 to 5 days in $10 \mathrm{mM} 3 \mathrm{AT}$ medium supplemented with histidine or NAC. Following the culture period, the cells were spotted onto rich medium to measure cell viability (Fig. 3A). There was no significant loss of viability of the wild-type cells treated with 3AT for up to 5 days (Fig. 3A-B), even though 3AT substantially reduces the growth rate of these cells (Fig. S1). In contrast, only $\sim 1 \%$ of $s t y l \Delta$ cells survived a two-day treatment with $3 \mathrm{AT}$ (Fig. $3 \mathrm{~A}$ ). Importantly, the reduced viability during this period was suppressed by the addition of histidine, emphasizing that starvation for this amino acid was central for the enhanced lethality accompanying the $3 \mathrm{AT}$ treatment of the $s t y 1 \Delta$ strain. Interestingly, the viability of sty $1 \Delta$ cells that was reduced after 2 days of starvation increased to $\sim 100 \%$ on day 5 (Fig. $3 \mathrm{~A})$. Illustrating this point, the sty $1 \Delta$ cells that were recovered after 5 days of starvation grew faster on YES medium (Fig. 3A). This finding suggests that after 3 or more days of starvation, the sty $1 \Delta$ culture generated genetic mutants resistant to $3 \mathrm{AT}\left(3 \mathrm{AT}^{\mathrm{R}}\right)$. Supporting this idea, a sensitivity assay using 3AT-containing plates confirmed that about $10 \%$ of the sty $1 \Delta$ cells that were recovered following 2 days of starvation were $3 \mathrm{AT}^{\mathrm{R}}$, whereas nearly $100 \%$ of sty $l \Delta$ cells that survived after 3 and 5 days of starvation were $3 \mathrm{AT}^{\mathrm{R}}$ (data not shown).

In an effort to examine if the reduced viability is due to oxidative stress, we tested the effect of the antioxidant, NAC. Its addition to the sty $1 \Delta$ cells enhanced viability for up to 3 days of $3 \mathrm{AT}$ treatment (Fig. 3A). However, at day 5 there was reduced survival of the sty $1 \Delta$ cells in the combined 3AT+NAC treatment (Fig. 3A). At this point the NAC addition to the 3AT liquid medium also suppressed the generation of $3 \mathrm{AT}^{\mathrm{R}}$ cells, which instead caused the extinction of the entire culture on day 5 (Fig. 3B). These results suggest that sty ${ }^{+}$function contributes to a significant delay in cell death induced by oxidative stress during histidine starvation. NAC can provide some protection to sty $1 \Delta$ cells against $3 \mathrm{AT}$ exposure for up to 3 days, but this anti-oxidant is not sufficient for longer treatment periods. In this sense, this shorter-term protection comes with a price. The $3 \mathrm{AT}^{\mathrm{R}}$ revertants that accumulated in the sty $1 \Delta$ cultures were absent when NAC was combined with $3 \mathrm{AT}$ in the medium (Fig. 3B).

styl $\Delta$ cells were longer during the growth in the $10 \mathrm{mM} 3 \mathrm{AT}$ medium (Fig. 3C), as observed under other stresses ${ }^{34}$. Thus, the observed decrease in $\mathrm{CFU}$ per $\mathrm{A}_{600}$ unit culture measured in Fig. $3 \mathrm{C}$ was potentially due to increased mass per cell and as a consequence of plating fewer cells. However, this possibility was excluded by measuring the average size of wild type and sty $1 \Delta$ cells. Within the first three days of starvation, the size of the sty $1 \Delta$ cells was 
only 2- to 4-fold larger than that of wild-type cells in the 3AT medium, and NAC addition reduced the size of the sty $1 \Delta$ cells only $<2$-fold at each growth time (Fig. 3C).

Together, these results suggest that 3AT-induced histidine starvation imposes oxidative stress, and $s t y 1^{+}$rescues the stress likely by expressing the CESR (Fig. 2A) (see Discussion also). In the absence of $s t y 1^{+}$, the stress appears to damage the yeast cells, leading to reduced viability. The generation of $3 \mathrm{AT}^{\mathrm{R}}$ cells could be due to DNA mutations or epigenetic changes. While the mechanism of this observation requires further examination, it is consistent with the idea that the cells grown in the presence of 3AT experience some sort of damage to chromosomes (indicated as "Damage" in Fig. 2A). The fact that NAC rescues the reduced viability of sty $1 \Delta$ cells for the first 3 days (Fig. 3A-B) suggests that the damage is due to oxidative stress, and more importantly, agrees with the idea that the major function of the Sty1 pathway, in this context, is to respond to oxidative stress.

\section{Int6/elF3e and Gcn2 elF2K also suppress cell death during histidine starvation}

We next addressed whether Int6/eIF3e and Gcn2 suppress cell death during histidine starvation, as observed for Sty1. Initially we carried out the experiment using $10 \mathrm{mM} 3 \mathrm{AT}$ in EMM medium, as performed previously (Fig. 3). However, the mutants deleted for int $6^{+}$or $g c n 2^{+}$did not display a reduced viability even when incubated for up to 7 days (data not shown). Thus, we incubated the mutants in the medium containing $30 \mathrm{mM}$ 3AT. Under these conditions, the wild-type yeast grew even more slowly than in the presence of $10 \mathrm{mM} 3 \mathrm{AT}$ and after day 2, they almost stopped growing (Fig. S1B, panel 1). Coincidentally, the viability of wild-type cells dropped to $\sim 15 \%$ in the 3AT medium during this period (Fig. $4 \mathrm{~A}-\mathrm{B}$, panels 1 ). In contrast, there was a significant reduction of viability of int $6 \Delta$ cells ( $\sim 1 \%$ survival) after 3 days of $3 \mathrm{AT}$ exposure (Fig. 4A-B, panels 2 ). The viability of gcn $2 \Delta$ cells also dropped more greatly ( $\sim 10 \%$ survival) than that for wild-type after $3(\mathrm{p}=0.05, \mathrm{n}=4)$ and 5 days ( $\mathrm{p}=003, \mathrm{n}=3$ ) of $3 \mathrm{AT}$ exposure (Fig. 4A-B, panels 3 ). This minor effect is consistent with the partial suppression of 3AT sensitivity of $g c n 2 \Delta$ cells by NAC, as observed in the dilution assays (Fig. 2C). As with styl $\Delta$ cells, NAC enhanced the viability of int $6 \Delta$ and $g c n 2 \Delta$ cells. Neither deletion resulted in a dramatic alteration in cell size during the experiments (Fig. 4C), reinforcing the idea that the differences observed in the CFU are due to cell death. These results suggest that Int6/eIF3e and Gcn2 are also required for suppressing cell death caused by histidine starvation, which likely result from oxidative damage.

As before for the sty $1 \Delta$ strain, we did find that, after 5 days of 3AT treatment, nearly all int $6 \Delta$ cells were rendered $3 \mathrm{AT}^{\mathrm{R}}$. By contrast, the $g c n 2 \Delta$ cells, defective for the eIF2K pathway, remained 3AT-sensitive (data not shown). These results suggest that histidine starvation induced cellular damage leading to genetic suppression, specifically in the absence of the Sty1 MAPK pathway or the suggested adjunct regulator, Int6 (Fig. 2A).

\section{Int6/elF3e is required for $\mathrm{H}_{2} \mathrm{O}_{2}$-induced oxidative stress}

To strengthen the idea that Int6/eIF3e is involved in endogenous oxidative stress induced by histidine starvation, we wished to determine if Int6/eIF3e is involved in stimulating the Sty1 pathway directly under $\mathrm{H}_{2} \mathrm{O}_{2}$-induced oxidative stress. Dilution assays in Fig. 5A indicated 
that int $6 \Delta$ substantially increased sensitivity to continuous $\mathrm{H}_{2} \mathrm{O}_{2}$ exposure in three different genetic backgrounds (rows 1-2, $h^{90}$ ade6-M216; rows 3-4, $h^{-}$ade6-M216; rows 5-7, $h^{-}$), as sty $1 \Delta$ did albeit more strongly (Fig. 5A). To directly test if int $6 \Delta$ reduced viability during exposure to $\mathrm{H}_{2} \mathrm{O}_{2}$ for a defined period, we treated the strains to high levels of $\mathrm{H}_{2} \mathrm{O}_{2}$ (1-4 $\mathrm{mM}$ ) for 4 hours and examined their viability after plating on YES medium agar plates. The int $6 \Delta$ cells were sensitive to exposure to $1 \mathrm{mM} \mathrm{H}_{2} \mathrm{O}_{2}$, while the majority of wild-type cells tolerated this level of exposure (Fig. 5B). Thus, Int6/eIF3e is involved in the oxidative damage response.

To examine the effect of int $6 \Delta$ on Atf1-dependent CESR transcription during $\mathrm{H}_{2} \mathrm{O}_{2}$-induced stress, a northern blot analysis was performed to determine the mRNA levels of several key CESR genes (atfl, pcrl, ctal and $g p d l)$ from wild-type or int $6 \Delta$ strains following exposure to $2 \mathrm{mM} \mathrm{H}_{2} \mathrm{O}_{2}$ for up to 180 minutes. In wild-type cells exposed to $\mathrm{H}_{2} \mathrm{O}_{2}$ there was increased levels of each of the transcripts (Fig. 5C and D). For each CESR gene, int6 $\Delta$ delayed and attenuated their accumulation. We also observed that int $6 \Delta$ reduced the Atf1 protein abundance prior to applying the stress (Fig. 5E). The reduced Atf1 protein abundance was not accompanied by a change in atf $1^{+}$mRNA levels (Fig. 5E), suggesting that int $^{+}$promotes atf $1^{+}$expression at the posttranscriptional level in a complex rich medium, as well as in a minimal medium ${ }^{12}$. Thus, the diminished CESR transcription observed in int $6 \Delta$ cells could at least partially result from lowered Atf1 protein abundance. These results indicate that int $6^{+}$is also required for the response to $\mathrm{H}_{2} \mathrm{O}_{2}$-induced oxidative stress by a mechanism involving regulation of $\operatorname{atf} 1^{+}$expression.

\section{Int6/elF3e, but not elF3h, plays a role in rescuing histidine starvation by enhancing atf1 ${ }^{+}$ expression}

At this point, the evidence relating Int6/eIF3e and the Sty1 pathway was that they are commonly involved in oxidative stress and that Int6/eIF3e enhances expression of atf $1^{+}$ encoding the transcription factor targeted by Sty ${ }^{12}$. To establish the genetic relationship between int $6^{+}$and atf $1^{+}$during histidine starvation, we performed a complementation assay. Fig. 6A indicates that the 3AT sensitivity of int $6 \Delta$ mutant was partially suppressed by overexpression of Atf1 and, as expected, by that of Int6/eIF3e. These results reinforce the idea that the enhanced expression of $a t f I^{+}$contributes to the resistance to histidine starvation conferred by int $6^{+}$(Fig. 2A).

To determine if the 3AT sensitivity of int $6 \Delta$ mutant is a general consequence of disruption of eIF3, we created and characterized a yeast mutant deleted for eif $3 h^{+}$encoding the $h$ subunit of eIF3. The eif $3 h \Delta$ strain, like int $6 \Delta$, substantially reduced the total protein synthesis rate compared to wild-type, as measured by ${ }^{35} \mathrm{~S}$-Met incorporation into total proteins (Fig. 6B and Table 1). Equal Coomassie staining of the total proteins indicates equal protein loading in this experiment (Fig. 6B, lanes 1-3). The reduction in protein synthesis was accompanied by an increase in the doubling time (Table 1). Despite this fact, the eif $3 h \Delta$ strain did not confer 3AT sensitivity (Fig. 6C). Therefore, the 3AT sensitivity is a specific phenotype associated with loss of the Int6/eIF3e subunit (see Discussion). 


\section{Transcriptional evidence for a feedback mechanism within Int6/elF3e-assisted Sty1- dependent response caused by histidine starvation}

Having gained evidence suggesting that Int6/eIF3e rescues oxidative damage during 3ATinduced starvation, we focused on our previous northern blot studies indicating that int6 $\Delta$ not only decreases the initial rate of CESR transcript $\left(a t f I^{+}, \mathrm{pcrl}^{+}, \mathrm{gpdl}^{+}\right.$, and $\mathrm{ctal}^{+}$, as used in Fig. 1) accumulation upon exposure to $30 \mathrm{mM} 3 \mathrm{AT}$, but also allowed extended accumulation of these transcripts, which peaks after 3 hrs of 3 AT treatment ${ }^{12}$ (also see Fig. $\mathrm{S} 2$ below). This extended transcriptional response was accompanied by the extended duration of Wis1-directed Sty 1 activation ${ }^{12}$. Thus, the delayed and extended CESR transcription appears to indicate an increasing oxidative signal that can activate Sty1 even in int $6 \Delta$ cells and eventually damage the cells.

To verify these trends at a genome-wide level, we examined the transcriptional microarray data of 3AT-treated int $6 \Delta$ cells. Of the 169 CESR transcripts induced by $30 \mathrm{mM} 3 \mathrm{AT}$ (termed cluster 2 genes in ${ }^{12}$ ), the abundance of $85 \%$ of these mRNAs (144 genes) was lower in int $6 \Delta$ cells than in wild-type after $1 \mathrm{hr}$ of $3 \mathrm{AT}$ addition, in agreement with their slower accumulation. Conversely, the abundance of $51 \%$ of these transcripts ( 87 genes) was higher in int $6 \Delta$ cells than in wild-type after $3 \mathrm{hrs}$ of $3 \mathrm{AT}$ addition. Again this is in agreement with the delayed accumulation. Together, expression of 61 CESR genes showed the combined lower expression at $1 \mathrm{hr}$ and higher expression at $3 \mathrm{hr}$ in int $6 \Delta$ cells after $3 \mathrm{AT}$ addition. This pattern is in agreement with the delayed and extended CESR transcription suggested by our northern blot experiments 12 .

To address if int $6 \Delta$ extends the duration of Atf1 transcriptional activity rather than, for example, the stability of the transcripts, we examined changes in chromatin structure at a Atf1-binding site (CRE, cAMP-response element) ${ }^{35}$. We chose $c t a 3^{+}$, encoding a P-type ATPase cation pump, because its expression was strongly enhanced after $3 \mathrm{hrs}$ of the stress application (Fig. 7A-B). As shown in Fig. 7C, micrococcal nuclease (MNase) sensitivity at a site near the cta3 CRE, indicative of the nucleosome remodeling therein, was increased at 0.5 to $1 \mathrm{hr}$ after 3-AT treatment in wild-type cells (arrows in the gel), coincident with cta3 mRNA and other CESR mRNA accumulation (Fig. 7A-B). In int6 $\Delta$ cells, the remodeling of the area near cta 3 CRE lasted longer and could be observed after $3 \mathrm{hr}$ of $3 \mathrm{AT}$ treatment (arrows in Fig. 7D, also see Fig. 6E for quantification of MNase sensitivity), again coinciding with the abundance of cta3 mRNA (Fig. 7A-B). Thus, int $6 \Delta$ extends the duration of remodeling of an Atf1-dependent gene during histidine starvation. Chromatin immunoprecipitation confirmed that Atf1 actually binds the cta3 CRE, although Atf1 was bound to the CRE before the stress, as observed for other CREs ${ }^{14}$, and the increase in Atf1 binding by $3 \mathrm{AT}$ treatment was minor though significant (KH, KA and $\mathrm{KO}$, unpublished data; see Materials and methods).

Together with our previous report ${ }^{12}$, these results support the idea that a Sty1-activating signal, most likely oxidative stress, builds up within 3AT-treated int $6 \Delta$ cells due to a failure to quickly antagonize the original (oxidative) stress and that the increased signal in turn activates Sty1. Thus, our results also suggest that a feedback loop operates within the 3ATinduced Sty1 pathway, as illustrated in Fig. 2A. However, we could not determine whether 
the original Sty1-activating signal, which quickly activated Sty1, within 15 min, on 3AT exposure ${ }^{12}$, is also an oxidative stress (see Discussion).

\section{Transcriptional evidence that Gen2 reduces oxidative stress during histidine starvation}

In agreement with the relationship of $g \mathrm{cn} 2^{+}$-regulated genes with oxidative stress, our cDNA microarray analysis indicated that $3 \mathrm{AT}$-induced genes requiring $g c n 2^{+}$(cluster $3{ }^{12}$ ) include genes potentially ameliorating oxidative damage, as listed in Table 2 . Grx4 is a nuclear glutaredoxin, antagonizing oxidative damage of the chromosomes ${ }^{36}$. SPAC1F12.06c encodes a predicted DNA repair endonuclease V, whereas SPCC18.09c encodes the yeast homologue of Aprataxin, a human protein that binds damaged DNA and is involved in DNA repair ${ }^{37}$. The expression of $y c t 1$, encoding a potential cysteine transporter ${ }^{38}$, would favor glutathione synthesis. Furthermore, cluster 3 includes many predicted mitochondrial proteins, of which $m m f l$, gorl and atml are likely to be involved in mitochondrial maintenance (Table 2), based on studies of the homologous S. cerevisiae genes ${ }^{39 ;} 40$. In particular, the S. cerevisiae mutant deleted for $A T M 1$, encoding a $\mathrm{Fe} / \mathrm{S}$ cluster precursor transporter, increases the level of glutathione, which protects against oxidative stress ${ }^{40}$. Thus, $g \mathrm{cn} 2^{+}$can promote expression of genes involved in mitochondrial maintenance and biogenesis, which can influence oxidative damage (Fig. 2A).

If $\mathrm{Gcn} 2$ alleviates oxidative damage, the lack of $g \mathrm{cn} 2^{+}$would cause oxidative stress in the presence of 3AT, which might in turn express a specific response. To test this idea, we analyzed genes that are specifically induced in 3AT-treated gcn $2 \Delta$ cells. Indeed, our reanalysis of expression profiling data of 3AT-treated gcn $2 \Delta$ cells ${ }^{12}$ revealed 217 genes,

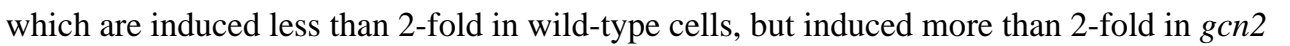
cells after $3 \mathrm{hr}$ of $3 \mathrm{AT}$ treatment. As shown in Fig. 8A, cluster analysis divided these genes into two groups, clusters 4 and 5 following the cluster numbers described previously ${ }^{12}$. Table S1 shows 121 genes belonging to clusters 4 and 5, not induced more than 2-fold in wild-type but induced by an even higher 2.4-fold in gcn2 $\Delta$ cells treated with $30 \mathrm{mM} 3 \mathrm{AT}$. The genes in cluster 4 encode heatshock proteins, redox enzymes, and proteins involved in protein degradation and mitochondrial maintenance. Cluster 4 generally overlaps with stress genes, especially with oxidative stress genes $\left(\mathrm{p}=2 \mathrm{e}^{-24}\right)$. The genes in this cluster also strongly overlap with the cluster 7 genes (Fig. 2 in Ref ${ }^{41}$ ) that are strongly induced by two oxidative compounds, menadione and $t$-butylhydroperoxide, but not by hydrogen peroxide $\left(\mathrm{p}=3 \mathrm{e}^{-12}\right.$ ) and with a set of genes (Fig. 4A in Ref ${ }^{41}$ ) whose transcription does not depend on a kinase or transcription factor known to drive the oxidative stress response, such as Sty1, Pmk1, Atf1, Pcr1, or Pap1 $\left(\mathrm{p}=2 \mathrm{e}^{-09}\right)$. Thus, the observed expression of cluster 4 genes is consistent with the model that this novel set of genes respond to oxidative damage generated in $g c n 2 \Delta$ cells (Fig. 8B). Cluster 5 genes encode proteins involved in protein folding or degradation and mitochondrial maintenance, again consistent with the generation of oxidative stress (Table S1). However, this cluster does not overlap with any known gene list (see Fig. 8B and Discussion).

\section{Sty1 MAPK stimulates Gcn2-dependent transcription by enhancing Gen2 activation}

We next examined the crosstalk between the Sty1 and Gen2 pathways in the 3AT-induced stress response. Immunoblotting with anti-phospho eIF2a antibodies confirmed that Gcn2 
phosphorylation of eIF2a peaks between $30 \mathrm{~min}$ and $1 \mathrm{hr}$ of 3AT addition (Fig. 9A).

Phosphorylation was absent when alanine was substituted for Ser-51 of eIF2a. Deletion of $g c n 2^{+}$significantly delayed eIF2a phosphorylation, suggesting that alternative eIF2Ks, Hri1 and/or Hri2, can partially compensate in response to 3AT. Importantly, the maximal Gcn2 phosphorylation of eIF2a is preceded by Sty 1 activation, which is at a maximum within the first $15 \mathrm{~min}$ of $3 \mathrm{AT}$ stress ${ }^{12}$. To test whether the early Sty1 activation can contribute to Gcn2 function, we examined the effect of sty $1 \Delta$ on 3 AT-induced eIF2a phosphorylation and the attendant Gcn2-dependent transcription. We found that sty $1 \Delta$ significantly delayed Gcn2 phosphorylation of eIF2a within the first $30 \mathrm{~min}$ of 3AT addition (Fig. 9A and B).

Moreover, sty $1 \Delta$ significantly delayed Gcn2-dependent gene transcription accordingly (Fig. 9C); in wild-type cells, the accumulation of the three Gcn2 target transcripts peaked at $1 \mathrm{hr}$ of 3AT-induced starvation, the same time as for the CESR transcription. Loss of Sty1 diminished this early peak response, and rather enhanced Gcn2-dependent gene transcription later especially after $5 \mathrm{hr}$ of starvation (Fig. 9C). These results indicate that sty $\mathrm{l}^{+}$can promote rapid Gcn2-dependent eIF2a phosphorylation and the attendant GAAC transcription during histidine starvation (Fig. 2A).

Because an increase in eIF2a phosphorylation was observed in a sty 1 mutant ${ }^{42}$, it was conceivable that the later enhancement of GAAC transcription in sty $1 \Delta$ cells after $5 \mathrm{hrs}$ of 3AT treatment was due to an increased level of eIF2a phosphorylation. To test this idea, we examined the eIF2a phosphorylation until $5 \mathrm{hrs}$ of $3 \mathrm{AT}$ treatment. However, styl $\Delta$ did not alter the level of eIF2a phosphorylation compared to wild-type after 3-5 hrs of 3AT treatment (Fig. 9B). Thus, an additional factor contributes to the styl $\Delta$-induced enhancement of GAAC transcription.

\section{Discussion}

The evidence presented here, suggesting that the oxidative stress response represents a major component of fission yeast response to 3AT-induced histidine starvation, is based on the viability assays of the mutants deleted for the $s t y 1^{+}, g c n 2^{+}$and int $6^{+}$genes, which are directly involved in the response to 3AT-induced starvation (Fig. 3-4), as well as transcriptional profiles (both northern blot and microarray) consistent with expression of potential antioxidant genes at the timing expected for individual mutations (Fig. 1, 7) ${ }^{12}$. Although the addition of NAC complimented the reduced viability caused by 3AT-induced starvation (Fig. 3-4), NAC or its cellular product, reduced glutathione, can have functions other than anti-oxidation, so the experiments with NAC do not necessarily prove an antioxidation function. However, our ferric-xylenol orange assay ${ }^{43}$ recently showed that the lipid fractions isolated from wild-type $S$. pombe, which had been treated for 3-24 hrs with 3AT in the same medium as we used here, was 2-3-fold more strongly peroxidized, and that NAC addition reduced this effect (NN, Kimberly Hall, Yuka Ikeda, Ruth Welti and KA, unpublished data), in agreement with the idea that the NAC indeed rescues oxidative damage within the 3AT-treated cells. Together with this finding and the transcriptional evidence indicating that int $6 \Delta$ delays and extends the duration of Sty1-activation and the attendant transcription ${ }^{12}$, we propose that a feedback mechanism, as illustrated in Fig. 2A, operates within the Sty1 pathway, and that Int6/eIF3e plays an important role in this regulation. 
The source of oxidative signals that leads to Sty 1 activation under the feedback response is likely to be complex. An example of the internal source of oxidation would include oxidative degradation of metabolic compounds in the peroxisomes which requires high catalase activity for detoxifying generated $\mathrm{H}_{2} \mathrm{O}_{2}$, or a change of mitochondrial respiration status that can occur during a shift from anaerobic to aerobic conditions. In support of the mitochondria-derived oxidation, the importance of mitochondrial maintenance during histidine starvation is suggested by possible Gcn2 regulation of genes involved in this process, both positively (cluster 3, Table 2) and negatively (cluster 5, Fig. 8 and Table S1).

However, we could not obtain clues to help us understand the mechanism whereby the original starvation signal quickly promoted Sty1 activation and attendant transcription, as observed in Fig. 1. In order to address this question, we examined the effect of NAC on 3AT-induced CESR transcription, but NAC had only a marginal effect on this robust transcriptional response (Fig. S2). This negative result rather suggests that Sty1 is rapidly activated by a feed-forward mechanism, without being mediated by an oxidative signal (? in Fig. 2A). A feed-forward mechanism can evolve as a result of repeated changes in the environment ${ }^{44}$. Shiozaki et al. previously showed that carbon source starvation also activates the Sty1 MAPK cascade, in this case directly via Mcs $4{ }^{45}$. Thus, it would be important to determine whether the nutritional stress arrangements that lead to Sty1 activation commonly result in the generation of endogenous oxidative stress.

\section{The role for Int6/elF3e in regulation of $\mathrm{atf1}^{+}$gene expression}

Here we also showed that atf $1^{+}$expression can rescue the 3AT sensitivity of an int $6 \Delta$ mutant (Fig. 3E), reinforcing that int $6^{+}$regulates atf $1^{+}$. How does Int6/eIF3e regulate $a t f 1^{+}$ expression? Int6/eIF3e is an important part of eIF3 ${ }^{23 ; 24}$, promoting general protein synthesis (Table 1 and Fig. 3) ${ }^{12}$. The atf $I^{+}$mRNA has a relatively long $5^{\prime}$-UTR of $\sim 300 \mathrm{bp}$, devoide of any uORFs, which has been shown to be important for translational control for other mRNAs ${ }^{46}$. Given that Int6/eIF3e forms an interface to eIF4F in humans ${ }^{26}$, the intact eIF3 with this subunit might promote translation of capped mRNAs with a relatively long $5^{\prime}$ UTR, including atf $1^{+}$mRNA. An alternative model suggested by the specific effect of int $6 \Delta$ on 3AT sensitivity, compared to that of eif3h (Fig. 6B-C and Table 1), states that Int6/ eIF3e more specifically interacts with a subset of mRNA including atf $1^{+}$mRNA. Mass spectrometry analysis of human eIF3 indicates that eIF3e is located in the proximity to the RNA-binding eIF3d subunit ${ }^{47 ; 48}$, raising the possibility that the eIF3e/eIF3d module can serve as a mRNA regulatory unit of eIF3. Combined sty $1 \Delta$ int $6 \Delta$ strains show stronger sensitivity to $3 \mathrm{AT}$ compared to single mutants ${ }^{12}$, suggesting that int $6^{+}$also regulates damage response pathway(s) other than the Sty1 pathway. Therefore, it would be important to address the molecular basis of the regulation of $a t f 1^{+}$expression by Int6/eIF3e and find additional targets regulated by this eIF3 subunit.

\section{Potential role for Gen2 in the response to endogenous oxidative stress during histidine starvation}

Our suggestion that Gcn2 may play a role in anti-oxidation (Table 2, Fig. 8) is consistent with the finding that the mammalian ISR, governed by eIF2Ks, contributes to glutathione biosynthesis and resistance to oxidative stress ${ }^{6}$. The expression of anti-oxidant clusters 4 
and 5 in $g c n 2 \Delta$ cells (Fig. 8) provides additional evidence that the Gcn2-dependent response includes a response to oxidative stress during histidine starvation. Of interest were the cluster 5 genes whose expression is repressed by $g \mathrm{cn} 2^{+}$and induced in its absence in a manner dependent on $\mathrm{hril}^{+}$and $\mathrm{hri2}^{+}$(Fig. 8). HRI eIF2 kinases possess a heme-binding site, which may be used to sense oxidative compounds ${ }^{1}$. In the absence of $g c n 2^{+}$, eIF2a is partially phosphorylated by 3AT treatment in a manner dependent on hril ${ }^{+}$and hri2 ${ }^{+12}$ (also see Fig. 9A, panel 4). Thus, Hri1/Hri2 appear to be activated by the oxidative stress, thereby stimulating the expression of cluster 5 by an unknown mechanism (Fig. 8B). As for the regulation of cluster 4, the gene induced most highly in gcn $2 \Delta$ cells (by 12 -fold) belongs to this cluster and encodes a potential transcription factor (Table S1), whose S. cerevisiae homolog, Mbf1p, is a co-activator of Gcn $4 p^{49}$. Thus, it would be intriguing to test whether this protein and an unidentified Gen2 target facilitate the transcription of this set of genes.

Sty1-mediated activation of Gcn2 (Fig. 9) would couple the major stress-activated MAPK pathway to translational control. Because exogenous $\mathrm{H}_{2} \mathrm{O}_{2}$ does not induce GAAC transcription (TU and KA, unpublished data), the coupling of Sty1 and Gcn2 appear to be restricted to specific stress arrangements, such as those involving nutrient starvation. Sty1 could activate Gcn2 directly or indirectly. The indirect mechanism may involve other signaling pathways, known to respond to nutritional stresses, such as TOR protein kinase pathways, which are proposed to regulate $S$. cerevisiae $\mathrm{Gcn} 2 \mathrm{p}{ }^{5051}$, and S. pombe Gcn2 specifically via Tor ${ }^{52}$. Extending the human relevance of this study, a coupling of ERK MAPK and Gen2 pathways is reported to occur following amino acid limitation of human hepatoma cells 53 .

\section{Implication to cancer biology}

Appropriate expression of anti-oxidation pathways is vital to tumor suppression ${ }^{54}$. For example, cells expressing activated $\mathrm{H}$-Ras produce $\mathrm{H}_{2} \mathrm{O}_{2}$, and the resulting oxidative damage is ameliorated by the human homologue of Sty1, p38, which suppresses H-Rasactivated tumorigenesis ${ }^{55}$. If the oxidative damage that we propose to be present in the int $6 \Delta$ yeast mutant, also occurs in mammalian cells with compromised Int-6/eIF3e activity, this might facilitate tumorigenesis by a process involving DNA mutations elicited during oxidative damage ${ }^{54}$. In addition, nutrient limitation is suggested to occur with progression of solid tumors. Accordingly, recent studies highlight pro-oncogenic role for eIF2Ks and attendant ISR expression in securing sufficient nutrients and alleviating oxidative damage ${ }^{7}$. However, oxidative damage, when untreated by the MAPK and/or eIF2K pathways, may also compound tumorigenesis, enhancing genetic diversity that could contribute to aggressiveness of tumors. Indeed, earlier studies implicated eIF2Ks in tumor suppression, and there is a strong correlation of up-regulation of protein synthesis with the progress of tumorigenesis ${ }^{2}$. In light of this study, it would be intriguing to investigate the role of eIF2Ks and ISR-directed anti-oxidation in preventing tumor initiation. 


\section{Experimental Procedures}

\section{Yeast strains}

Yeast S. pombe strains used in this study are listed in Table 1. We used strains prototrophic for amino acid biosynthesis in order to address resistance to 3-amino triazole (3AT), an inhibitor of histidine synthesis. For this purpose we used transformation with leul $1^{+}$or his $7^{+}$ -encoding plasmids, to convert leucine and/or histidine auxotrophy of previously constructed strains. Accordingly, strains KAY793 and KAY794, are transformants of KS2096 ${ }^{56}$ and CA220 ${ }^{57}$ respectively, carrying pREP41X $\left(\right.$ leu $\left.I^{+}\right)$. KAY852 is a transformant of JM1505 58 carrying pREP41X $\left(\right.$ leul $\left.{ }^{+}\right)$and pEA500 $\left(\right.$his $\left.7^{+}\right)$.

KAY649 (eif3hD) was constructed by introducing the eif3h ${ }^{+}$(SPAC821.05) disruption DNA, generated by PCR using oligos eIF3h-FW and eIF3h-RV (Table 2) and pKS-FA-ura4 (provided by Y. Watanabe, University of Tokyo) as a template. pKS-FA-ura4 is a derivative of pKS-ura $4{ }^{59}$ carrying the same primer-binding site as those of pFA6a derivatives. The resulting disruption DNA carries $\mathrm{ura}^{+}$in the reverse orientation relative to eif $3 h^{+}$. The integration of the disruption DNA into eif $3 h^{+}$was confirmed by PCR using a pair of oligonucleotides, one binding to a chromosomal site outside of the region present in the eif $3 \mathrm{~h}^{+}$disruption DNA and the other binding to $\mathrm{ura}^{+}$- coding region, namely eIF3h-up and ura4-midF and eIF3h-down and ura4-midR, respectively (Table 2).

KAY586 was prepared by converting the ura4-D18 locus of JY879 ( $h^{90}$ ade6-M210 leul-32 ura4-D18) (provided by M. Yamamoto, University of Tokyo) into $\mathrm{ura}^{+}$by transformation with the PCR-synthesized $\mathrm{rra}^{+}$fragment, as described ${ }^{12}$. Then, KAY587 was created by introducing int $6 \Delta$ by transformation with the PCR-synthesized int $6 \Delta$ : :kanMX fragment, as described ${ }^{23}$.

\section{Yeast media}

We used the complex rich medium YES and the defined medium EMM throughout our study ${ }^{60}$. To study histidine starvation by the addition of 3AT, we omitted histidine in the media and used minimal EMM medium or complete EMM medium supplemented with amino acids and other nutrients but lacking histidine (EMM-C-his), as described ${ }^{12}$. To study the effect of N-acetyl cysteine (NAC) (Fisher Chemical O1049), we used the minimal EMM supplemented with adenine (EMM+Ade) or EMM dropout with complete amino acids and other supplements, as described ${ }^{12}$. We determined that NAC was effective when its concentration was 4 to 5 times higher than $3 \mathrm{AT}$ in the EMM+Ade medium. Thus, $40 \mathrm{mM}$ NAC was supplemented with the EMM+Ade medium containing $10 \mathrm{mM}$ 3AT. Likewise, $120 \mathrm{mM}$ NAC was supplemented with the EMM+Ade medium containing $30 \mathrm{mM} 3 \mathrm{AT}$. To add these NAC concentrations to the EMM medium, a stock solution of NAC was prepared in EMM to a final concentration of $500 \mathrm{mM}$, which was then neutralized to $\mathrm{pH} 5.6 \mathrm{by} \mathrm{KOH}$, and filter-sterilized.

\section{Yeast growth and viability assays}

Yeast were grown at the permissive temperature of $30^{\circ} \mathrm{C}$ throughout the study. To determine the titer of yeast for both the drug sensitivity and viability assays, we spotted $5 \mathrm{ml} 0.15 \mathrm{~A}_{600}$ 
units of culture, or 10-fold and 100-fold dilutions of this culture preparation, onto the agar plates and incubated the plates at $30^{\circ} \mathrm{C}$. For $3 \mathrm{AT}$ sensitivity assays, spotted cultures were incubated in medium containing the indicated concentrations of 3AT, NAC, and histidine. For the viability assays following 3AT-induced histidine starvation, fresh overnight cultures of yeast were inoculated into $\sim 3 \mathrm{ml}$ liquid EMM+Ade medium with the indicated concentrations of NAC, histidine, and 3AT. The cultures were initiated at $\mathrm{A}_{600} \sim 0.3$ with constant agitation at $30^{\circ} \mathrm{C}$, and the aliquots were periodically removed to measure the absorbance at $600 \mathrm{~nm}$, which was subsequently plotted against the growth time. Additionally, serially diluted cultures were spotted onto the YES agar plates, incubated at $30^{\circ} \mathrm{C}$ for 2 days, and photographed. Colonies formed on each spot were counted to determine the viability, as presented by colony forming units (CFU) per $\mathrm{A}_{600}$. If two or more serially diluted spots contained well-dispersed colonies, the CFU per $\mathrm{A}_{600}$ values obtained from each spot were averaged to determine the viability value for that condition. Three independent viability assays were performed.

For viability assays with $\mathrm{H}_{2} \mathrm{O}_{2}$, cells were grown to $\mathrm{A}_{600}=0.5$ and then $\mathrm{H}_{2} \mathrm{O}_{2}$ was added at the different final concentrations. After treatment for $4 \mathrm{hrs}$, the culture was withdrawn, diluted and spotted onto YES plates and the plate was incubated for 2 days.

\section{Biochemical and molecular biology methods}

Standard biochemical, genetic, and molecular biology techniques were used throughout the study. Northern and western blot assays were performed as described ${ }^{12}$, using ${ }^{32} \mathrm{P}$-probes generated by PCR with the pair of primers as listed in Table 2 and affinity-purified anti-Atf 1 antibodies ${ }^{15}$, respectively. The total protein synthesis rate was measured by ${ }^{35} \mathrm{~S}$-methionine incorporation, also as described ${ }^{15}$. Statistical analyses used $\mathrm{T}$ test.

To perform the analysis of nucleosome structures, crude chromatin fractions from 3ATtreated cells were digested partially with 0,20 , or $30 \mathrm{U} / \mathrm{ml}$ MNase, and DNA was purified for complete HpaII digestion and gel electrophoresis ${ }^{35}$. The position of MNase-cleavage was determined by Southern blot hybridization to the cleavage products using ${ }^{32} \mathrm{P}-\mathrm{DNA}$ probe specific to a part of the $c t a 3^{+}$coding region. Primers used to amplify the labeled probe are listed in Table 2. To confirm Atf1-binding to the $c t a 3^{+}$CRE, we performed chromatin immunoprecipitation using a strain encoding Atf1-HA and anti-HA antibodies, as essentially described ${ }^{14}$. Briefly, the area of $c t a 3$ CRE bound to Atf1-HA was immunoprecipitated with anti-HA antibodies, and detected by quantitative real-time PCR with the primers listed in Table 2.

\section{Microarray analysis}

Microarray data generated previously ${ }^{12}$ was re-analyzed in GeneSpring (Agilent Technologies, Palo Alto, CA). The significance of overlap between different gene lists was calculated in GeneSpring by using a standard Fisher's exact test, and the $\mathrm{p}$ values were adjusted with a Bonferroni multiple testing correction.

\section{Supplementary Material}

Refer to Web version on PubMed Central for supplementary material. 


\section{Acknowledgments}

We thank E. Boye, C. Hoffman, J. Millar, J. Petersen, K. Shiozaki, Y. Watanabe and M. Yamamoto for timely gift of materials, K. Hall, Y. Ikeda, and R. Welti for sharing results before publication and H. Masai for stimulating discussion. This work was supported by the NCRR K-INBRE pilot grant P20 RR016475, Innovative Award from KSU Terry Johnson Cancer Center and NIH GM67481 to KA, and by NIH GM49164 to RW.

\section{References}

1. Dever, TE.; Dar, AC.; Sicheri, F. The eIF2a kinase. In: Mathews, MB.; Sonenberg, N.; Hershey, JWB., editors. Translational Control in Biology and Medicine. Cold Spring Harbor Lab Press; Cold Spring Harbor, NY: 2007. p. 319-344.

2. Schneider, RJ.; Sonenberg, N. Translational control in cancer development and progression. In: Mathews, MB.; Sonenberg, N.; Hershey, JWB., editors. Translational Control in Biology and Medicine. Cold Spring Harbor Lab Press; Cold Spring Harbor, NY: 2007. p. 401-431.

3. Martindale JL, Holbrook NJ. Cellular response to oxidative stress: Signaling for suicide and survival. J Cell Phys. 2003; 192:1-15.

4. Bi M, Naczki C, Koritzinsky M, Fels D, Blais J, Hu N, Harding H, Novoa I, Varia M, Raleigh J, Scheuner D, Kaufman RJ, Bell J, Ron D, Wouters BG, Koumenis C. ER stress-regulated tanslation increases tolerance to extreme hypoxia and promotes tumor growth. EMBO J. 2005; 24:3470-3481. [PubMed: 16148948]

5. Liu L, Wise DR, Diehl JA, Simon MC. Hypoxic reactive oxygen species regulate the integrated stress response and cell survival. J Biol Chem. 2008; 283:31153-31162. [PubMed: 18768473]

6. Harding HP, Zhang Y, Zeng H, Novoa I, Lu PD, Calfon M, Sadri N, Yun C, Popko B, Paules R, Stojdl DF, Bell JC, Hettmann T, Leiden JM, Ron D. An integrated stress response regulates amino acid metabolism and resistance to oxidative stress. Molecular Cell. 2003; 11:619-633. [PubMed: 12667446]

7. Ye J, Koumenis C. ATF4, an ER stress and hypoxia-inducible transcription factor and its potential role in hypoxia tolerance and tumorigenesis. Curr Mol Med. 2009; 9:411-416. [PubMed: 19519398]

8. Blais JD, Addison CL, Edge R, Falls T, Zhao H, Wary K, Koumenis C, Harding H, Ron D, Holcik $\mathrm{M}$, Bell JC. PERK-dependent translational regulation promotes tumor cell adaptation and angiogenesis in response to hypoxic stress. Mol Cell Biol. 2006; 26:9519-9532.

9. Zhan K, Vattem KM, Bauer BN, Dever TE, Chen JJ, Wek RC. Phosphorylation of eukaryotic initiation factor 2 by heme-regulated inhibitor kinase-related protein kinases in Schizosaccharomyces pombe is important for resistance to environmental stress. Mol Cell Biol. 2002; 22:7134-7146. [PubMed: 12242291]

10. Zhan K, Narasimhan J, Wek RC. Differential activation of eIF2 kinases in response to cellular stresses in Schizosaccharomyces pombe. Genetics. 2004; 168:1867-1875. [PubMed: 15611163]

11. Natarajan K, Meyer MR, Jackson BM, Slade D, Roberts C, Hinnebusch AG, Marton MJ. Transcriptional profiling shows that Gen $4 \mathrm{p}$ is a master regulator of gene expression during amino acid starvation in yeast. Mol Cell Biol. 2001; 21:4347-4368. [PubMed: 11390663]

12. Udagawa T, Nemoto N, Wilkinson C, Narashimhan J, Watt S, Jiang L, Zook A, Jones N, Wek RC, Bähler J, Asano K. Int6/eIF3e promotes general translation and Atf1 abundance to modulate Sty1 MAP kinase-dependent stree response in fission yeast. J Biol Chem. 2008; 283:22063-22075. [PubMed: 18502752]

13. Ikner A, Shiozaki K. Yeast signaling pathways in the oxidative stress response. Mut Res. 2005; 569:13-27. [PubMed: 15603750]

14. Reiter W, Watt S, Dawson K, Lawrence CL, Bähler J, Jones N, Wilkinson CRM. Fission yeast MAP kinase Sty1 is recruited to stress-induced genes. J Biol Chem. 2008; 283:9945-9956. [PubMed: 18252721]

15. Lawrence CL, Maekawa H, Worthington JL, Reiter W, Wilkinson CRM, Jones N. Regulation of Schizosaccharomyces pombe Atf1 protein levels by Sty1-mdeiated phosphorylation and heterodimerrization with Pcr1. J Biol Chem. 2007; 282:5160-5170. [PubMed: 17182615] 
16. Chen D, Toone WM, Mata J, Lyne R, Burns G, Kivinen K, Brazma A, Jones N, Bähler J. Global transcriptional response of fission yeast to environmental stress. Mol Biol Cell. 2003; 14:214-229. [PubMed: 12529438]

17. Marchetti A, Buttitta F, Miyazaki S, Gallahan D, Smith GH, Callahan R. Int-6, a highly conserved, widely expressed gene, is mutated by mouse mammary tumor virus in mammary preneoplasia. $\mathrm{J}$ Virol. 1995; 69:1932-1938. [PubMed: 7853537]

18. Asano K, Merrick WC, Hershey JWB. The translation initiation factor eIF3-p48 subunit is encoded by int- 6 , a site of frequent integration by the mouse mammary tumor virus genome. J Biol Chem. 1997; 272:23477-23480. [PubMed: 9295280]

19. Hinnebusch, AG.; Dever, TE.; Asano, K. Mechanism of translation initiation in the yeast Saccharomyces cerevisiae. In: Mathews, MB.; Sonenberg, N.; Hershey, JWB., editors. Translational Control in Biology and Medicine. Cold Spring Harbor Lab Press; Cold Spring Harbor, NY: 2007. p. 225-268.

20. Rasmussen SB, Kordon E, Callahan R, Smith GH. Evidence for the transforming activity of a truncated Int6 gene, in vitro. Oncogene. 2001; 20

21. Mayeur GL, Hershey JWB. Malignant transformation by the eukaryotic translation initiation factor 3 subunit p48 (eIF3e). FEBS Letters. 2002; 514:49-64. [PubMed: 11904180]

22. Mack DL, Boulanger CA, Callahan R, Smith GH. Expression of truncted Int6/eIF3e in mammary alveolar epithelium leads to persistent hyperplasia and tumorigenesis. Breast Cancer Res. 2007; 9:R42. [PubMed: 17626637]

23. Akiyoshi Y, Clayton J, Phan L, Yamamoto M, Hinnebusch AG, Watanabe Y, Asano K. Fission yeast homolog of murine Int-6 protein, encoded by mouse mammary tumor virus integration site, is associated with the conserved core subunits of eukaryotic translation initiation factor 3. J Biol Chem. 2001; 276:10056-10062. [PubMed: 11134033]

24. Zhou C, Arslan F, Wee S, Krishnan S, Ivanov AR, Oliva A, Leatherwood J, Wolf DA. PCI proteins eIF3e and eIF3m define distinct translation initiation factor 3 complexes. BMC Biol. 2005; 3:14. [PubMed: 15904532]

25. Sha Z, Brill LM, Cabrera R, Kleifeld O, Scheliga JS, Glickman MH, Chang EC, Wolf DA. The eIF3 Interactome reveals the translasome, a supercomplex linking protein synthesis and degradation machineries. Mol Cell. 2009; 36:142-152.

26. LeFebvre AK, Korneeva NL, Trutschl M, Cvek U, Duzan RD, Bradley CA, Hershey JWB, Rhoads RE. Translation initiation factor eIF4G-1 binds to eIF3 through the eIF3e subunit. J Biol Chem. 2006; 281:22917-22932. [PubMed: 16766523]

27. Masutani M, Sonenberg N, Yokoyama S, Imataka H. Reconstitution reveals the functional core of mammalian eIF3. EMBO J. 2007; 26:3373-3383. [PubMed: 17581632]

28. Ueda M, Kinoshita H, Yoshida T, Kamasawa N, Osumi M, Tanaka A. Effect of catalase-specific inhibitor 3-amino-1,2,4-triazole on yeast peroxisomal catalase in vivo. FEMS Microbiol Lett. 2003; 219:93-98. [PubMed: 12594029]

29. Kanoh J, Watanabe Y, Ohsugi M, Iino Y, Yamamoto M. Schizosaccharomyces pombe gad $7^{+}$ encodes a phosphorpotein with a bZIP domain, which is required for proper G1 arreset and gene expression under nitrogen starvation. Genes Cells. 1996; 1:391-408. [PubMed: 9135083]

30. Sansó M, Gogol M, Ayté J, Seidel C, Hidalgo E. Transcription factors Pcr1 and Atf1 have distinct roles in stress- and Sty1-dependent gene regulation. Eukaryot Cell. 2008; 7:826-835. [PubMed: 18375616]

31. Ohmiya R, Yamada H, Nakashima K, Aiba H, Mizuno T. Osmoregulation of fission yeast: cloning of two distinc genes encoding glycerol-3-phosphate dehydrogenase, one of which is responsible for osmotolerance for growth. Mol Microbiol. 1995; 18:963-973. [PubMed: 8825100]

32. Morigasaki S, Shimada K, Ikner A, Yanagida M, Shiozaki K. Glycolytic enzyme GAPDH promotes peroxide stress signaling through multistep phosphorelay to a MAPK cascade. Mol Cell. 2008; 30:108-113. [PubMed: 18406331]

33. Tvegård T, Soltani H, Skjølberg HC, Krohn M, Nilssen EA, Kearsey SE, Grallert B, Boye E. A novel checkpoint mechanism regulating the G1/S transition. Genes Dev. 2007; 21:649-654. [PubMed: 17369398] 
34. Shiozaki K, Russell P. Cell-cycle control linked to extracellular environment by MAP kinase pathway in fission yeast. Nature. 1995; 378:739-743. [PubMed: 7501024]

35. Hirota K, Hasemi T, Yamada T, Mizuno Ki, Hoffman CS, Shibata T, Ohta K. Fission yeast global repressors regulate the specificity of chromatin alteration in response to distinct environmental stresses. Nucl Acids Res. 2004; 32:855-862. [PubMed: 14762213]

36. Chung WH, Kim KD, Roe JH. Localization and function of three monothiol glutaredoxins in Schizosaccharomyces pombe. Biochem Biophys Res Commun. 2005; 330:604-610. [PubMed: 15796926]

37. Deshpande GP, Hayles J, Hoe KL, Kim DU, Park HO, Hartsuiker E. Screening a genome wide $S$. pombe deletion library identifies novel genes and pathways involved in the DNA damage response. DNA Repair. 2009; 8:672-679. [PubMed: 19264558]

38. Kaur J, Bachhawat AK. Ycy1p, a novel, high-affinity, cysteine-specific transporter from the yeast Saccharomyces cerevsiae. Genetics. 2007; 176:877-890. [PubMed: 17435223]

39. Oxelmark E, Marchini A, Malanchi I, Magherini F, Jaquet L, Hajibagheri MA, Blight KJ, Jauniaux JC, Tommasino M. Mmflp, a novel yeast mitochondrial protein conserved throughout evolution and involved in maintenance of the mitochondrial genome. Mol Cell Biol. 2000; 20:7784-7797. [PubMed: 11003673]

40. Kispal G, Csere P, Prohl C, Lill R. The mitochondrial proteins Atm1p and Nfs1p are essential for biogenesis of cytosolic Fe/S proteins. EMBO J. 1999; 14:3981-3989. [PubMed: 10406803]

41. Chen D, Wilkinson CRM, Watt S, Penkett CJ, Toone WM, Jones N, Bähler J. Multiple Pathways Differentially Regulate Global Oxidative Stress Responses in Fission Yeast. Mol Biol Cell. 2008; 19:308-317. [PubMed: 18003976]

42. Dunand-Sauthier I, Walker CA, Narashimhan J, Pearce AK, Wek RC, Humphrey TC. Stressactivated protein kinase pathway functions to support protein synthesis and translational adaptation in response to environmental stress in fission yeast. Eukaryot Cell. 2005; 4:1785-1793. [PubMed: 16278445]

43. Fukuzawa K, Fujisaki A, Akai K, Tokumura A, Terao J, Gebicki JM. Measurement of phosphatidylcholine hydroperoxides in solution and in intact membranes by the ferric-xylenol orange assay. Anal Biochem. 2006; 359:18-25. [PubMed: 17049475]

44. Mitchell A, Romano GH, Groisman B, Yona A, Dekel E, Kupiec M, Dahan O, Pilpel Y. Adaptive prediction of environmental changes by microorganisms. Nature. 2009; 460:220-224. [PubMed: 19536156]

45. Shiozaki K, Shiozaki M, Russell P. Mcs4 mitotic catastrophe suppressor regulates te fission yeast cell cycle through the Wik1-Wis1-spc1 kinase cascade. Mol Biol Cell. 1997; 8:409-419. [PubMed: 9188094]

46. Wilhelm B, Marguerat S, Watt S, Schubert F, Wood V, Goodhead I, Penkett CJ, Rogers J, Bähler J. Dynamic repertoire of a eukaryotic transcriptome surveyed at single-nucleotide resolution. Nature. 2008; 453:1239-1243. [PubMed: 18488015]

47. Asano K, Vornlocher HP, Richter-Cook NJ, Merrick WC, Hinnebusch AG, Hershey JWB. Structure of cDNAs encoding human eukaryotic initiation factor 3 subunits: possible roles in RNA binding and macromolecular assembly. J Biol Chem. 1997; 272:27042-27052. [PubMed: 9341143]

48. Zhou M, Sandercock AM, Fraser CS, Ridlova G, Stephens E, Schenauer MR, Yokoi-Fong T, Barsky D, Leary JA, Hershey JWB, Doudna JA, Robinson CV. Mass spectrometry reveals modularity and a complete subunit interaction map of the eukaryotic translation factor eIF3. Proc Natl Acad Sci USA. 2008; 105:18139-18144. [PubMed: 18599441]

49. Takemaru K, Harashima S, Ueda H, Hirose S. Yeast coactivator MBF1 mediates GCN4-dependent transcriptional activation. Mol Cell Biol. 1998; 18:4971-4976. [PubMed: 9710580]

50. Cherkasova VA, Hinnebusch AG. Translational control by TOR and TAP42 through dephosphorylation of eIF2 kinase GCN2. Genes Dev. 2003; 17:859-872. [PubMed: 12654728]

51. Staschke KA, Dey S, Zaborske JM, Palam LR, McClintick JN, Pan T, Edenberg HJ, Wek RC. Integration of general amino acid control and TOR regulatory pathways in nitrogen assimilation in yeast. J Biol Chem. 2010; 285:16893-16911. [PubMed: 20233714] 
52. Petersen J, Nurse P. TOR signalling regulates mitotic commitment through the stress MAP kinase pathway and the Polo and Cdc2 kinases. Nat Cell Biol. 2007; 9:1-10. [PubMed: 17199123]

53. Thiaville MM, Pan YX, Gjymishka A, Zhong C, Kaufman RJ, Kilberg MS. MEK signaling is required for phosphorylation of eIF2a following amino acid limitation of HepG2 human hepatoma cells. J Biol Chem. 2008; 283:10848-10857. [PubMed: 18287093]

54. Kennedy NJ, Cellurale C, Davis RJ. A radical role for p38 MAPK in tumor initiation. Cancer Cell. 2007; 11:101-103. [PubMed: 17292820]

55. Dolado I, Swat A, Ajenjo N, De Vita G, Cuadrado A, Nebreda AR. p38a MAP kinase as a sensor of reactive oxygen species in tumorigenesis. Cancer Cell. 2007; 11:191-205. [PubMed: 17292829]

56. Shiozaki K, Shiozaki M, Russell P. Heat stress activates fission yeast Spc1/Sty1 MAPK by a MEKK-independent mechanism. Mol Biol Cell. 1998; 9:1339-1349. [PubMed: 9614178]

57. Nguyen AN, Lee A, Place W, Shiozaki K. Multistep phosphorelay proteins transmit oxdative stress signals to the fission yeast stress-activated protein kinase. Mol Biol Cell. 2000; 11:1169-1181. [PubMed: 10749922]

58. Shieh JC, Wilkinson MG, Millar JBA. The Win1 mitotic regulator is a component of the fission yeast stress-activated Sty1 MAKP pathway. Mol Biol Cell. 1998; 9:311-322. [PubMed: 9450957]

59. Bähler J, Wu JQ, Longtine MS, Shah NG, McKenzie A 3rd, Steever AB, Wach A, Philippsen P, Pringle JR. Heterologous modules for efficient and versatile PCR-based gene targeting in Schizosaccharomyces pombe. Yeast. 1998; 14:943-951. [PubMed: 9717240]

60. Moreno S, Klar A, Nurse P. Molecular genetic analysis of the fission yeast Schizosaccharomyces pombe. Methods Enzymol. 1991; 194:795-823. [PubMed: 2005825]

61. Lyne R, Burns G, Mata J, Penkett CJ, Rustici G, Chen D, Langford C, Vetrie D, Bähler J. Wholegenome microarrays of fission yeast: characteristics, accuracy, reproducibility, and processing of array data. BMC Genom. 2003; 4:27. 
Histidine-starved yeast loses viability likely due to oxidative damage.

Stress-activated Sty1 MAPK and Gcn2 eIF2K rescue this oxidative damage.

Int6/eIF3e assists the antioxidation function of the Sty1 pathway.

Int6/eIF3e does so by enhancing expression of Atf1 targeted by Sty1. 

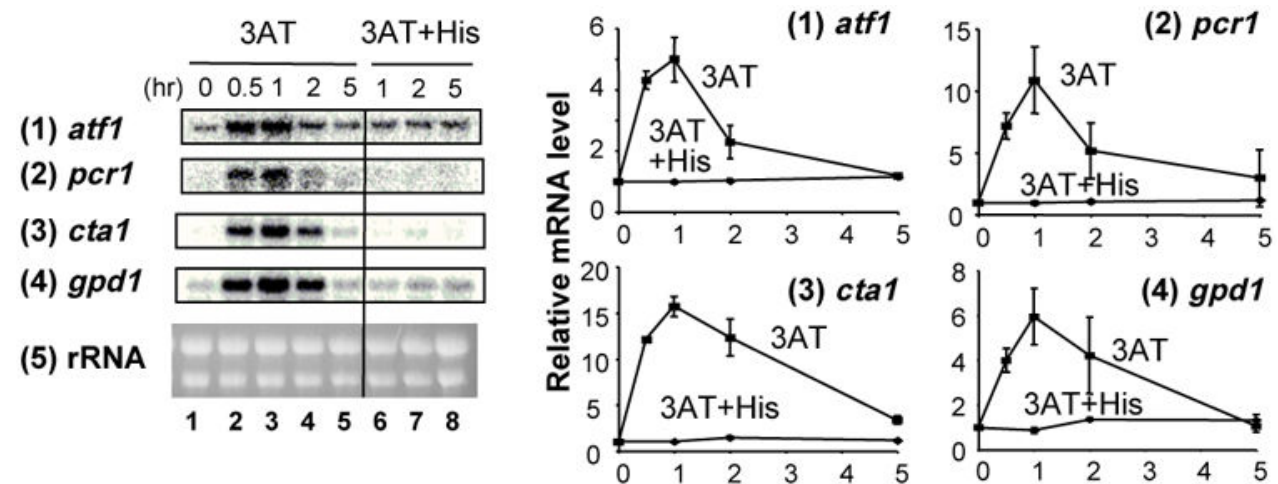

$\begin{array}{llllll}1 & 3 & 4 & 5 & 6 & 7\end{array}$



Time after 3AT treatment (hr)

Fig. 1. Effect of histidine on 3AT-induced CESR transcription A wild-type strain (KAY641) was grown exponentially in the EMM-C-his medium and split into two cultures. One was starved for histidine by adding $30 \mathrm{mM}$ 3AT (lanes 1-5) and the other was supplemented with $30 \mathrm{mM}$ 3AT and $60 \mathrm{mM}$ histidine simultaneously (lanes 6-8). Portions of the culture were withdrawn at indicated times and mRNA levels were analyzed by northern blot analysis using probes specific for genes listed to the left. EtBr-staining of rRNA was included as a loading control ${ }^{12}$. Graphs to the right show the time course for the levels of indicated mRNAs compared to the value at time 0 as 1 (lanes 1), with bars indicating $\mathrm{SD}(\mathrm{n}=2)$. In the graph for $3 \mathrm{AT}+\mathrm{His}$, error bars are smaller than the size of the symbols. 

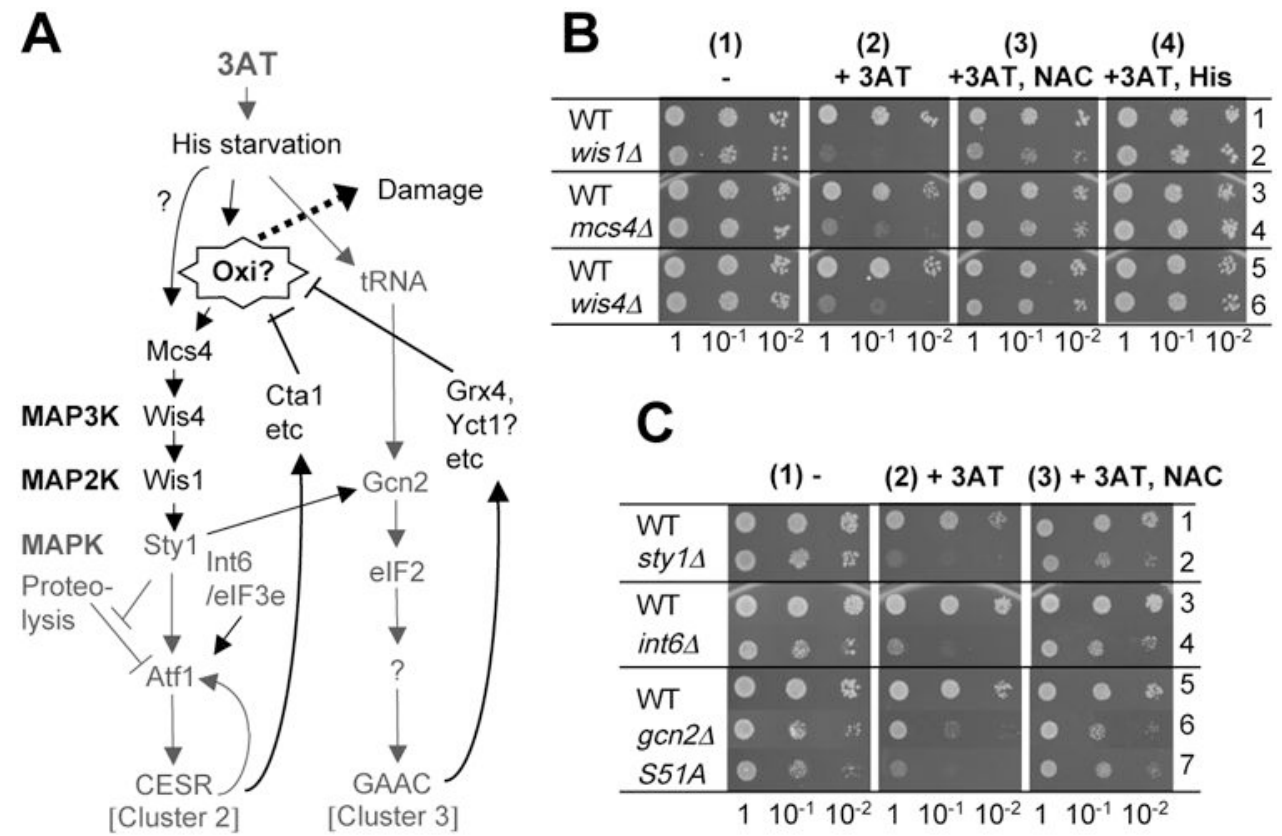

Fig. 2. Genetic evidence that a canonical Sty1 pathway, Int6/eIF3e and Gcn2 specifically promote oxidative stress response during histidine starvation

(A) Model of 3AT-induced Sty1 and Gcn2 pathways in fission yeast. 3AT-induced histidine (His) starvation activates not only the Gcn2-dependent pathway (cluster 3, right column) but also the Sty1-dependent pathway (cluster 2, left column). Here it is proposed that at least one of the Sty1 activating signals is endogenous oxidation (Oxi), which would cause cellular damage (Damage) if the products of both the pathways cannot antagonize the oxidative reagents (stopped bars towards Oxi?). This model was modified from the original model described in Ref. ${ }^{12}$. Dark gray letters and lines indicate a part of the pathways suggested by previous studies ${ }^{12}$. Black letters and lines indicate a part of the pathway suggested from this study. (B-C) Effect of NAC on the 3AT-sensitvity of different mutants. Cultures of the indicated mutants and their wild-type (WT) controls were diluted to $\mathrm{A}_{600}=0.15$, and $5 \mathrm{ml}$ of this and 10-fold serial dilutions were spotted onto EMM plus adenine agar plates supplemented without (panels 1) or with $5 \mathrm{mM} 3 \mathrm{AT}$ (panels 2), $5 \mathrm{mM} 3 \mathrm{AT}$ and $20 \mathrm{mM}$ NAC (panels 3), or $5 \mathrm{mM} 3 \mathrm{AT}$ and $10 \mathrm{mM}$ histidine (His) (panel 4 in A). However, for rows 5 and 6 in Fig. 2B, we used $8 \mathrm{mM}$ 3AT, $40 \mathrm{mM} \mathrm{NAC}$, and $16 \mathrm{mM}$ histidine. Plates were incubated for 4 (panels 1 and 4) and 6-7 (panels 2 and 3) days. Here we used minimal medium without amino acid supplements to promote incorporation of NAC and histidine. Strains used in (B) are JP3 (row 1), JP260 (row 2), KAY793 (row 3), KAY794 (row 4), KAY456 (row 5), and KAY852 (row 6), whereas in (C), we used KAY641 (rows 1 and 3), KAY640 (row 2), KAY647 (row 4), WY764 (row 5), KAY406 (row 6), and JP436 (row 7) (Table 1). 

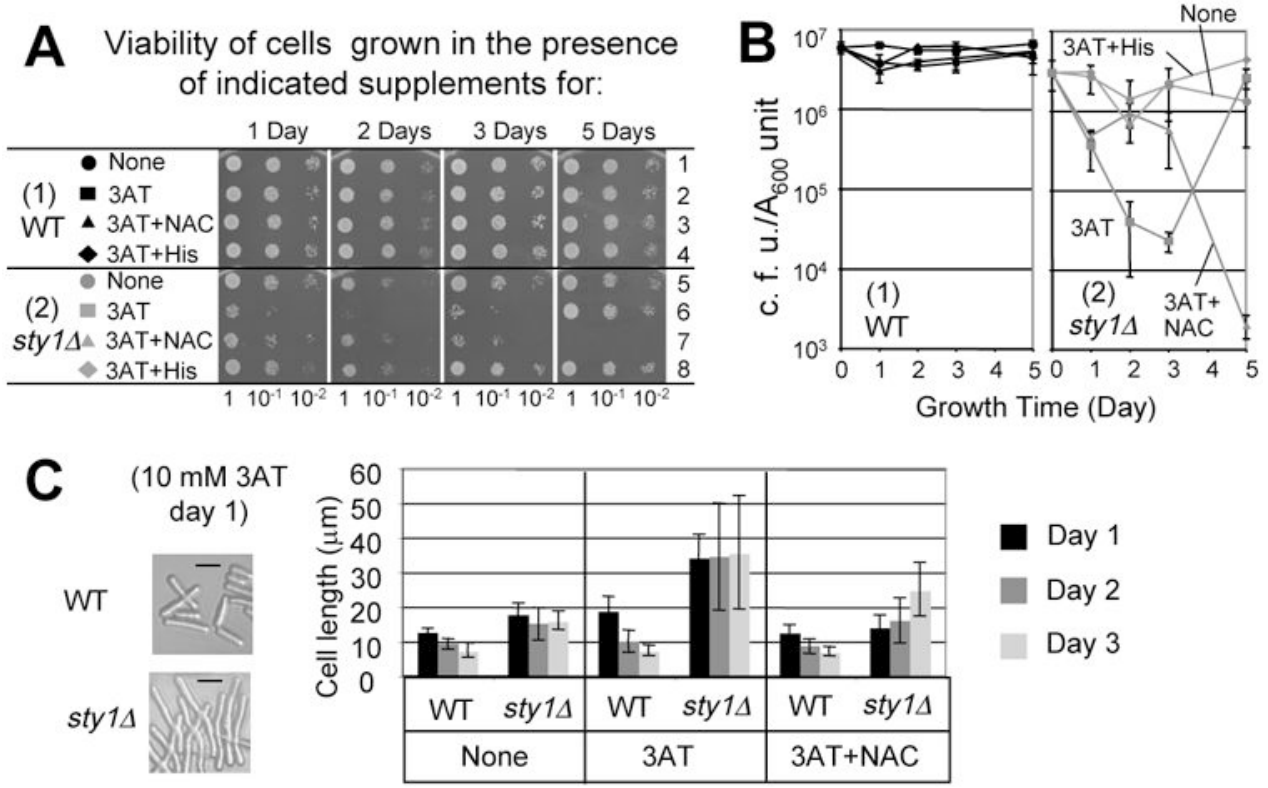

Day 1

Day 2

Day 3

Fig. 3. Sty1 MAPK suppresses stress-induced death and mutagenesis during histidine starvation (A) Viability assays in the presence of $10 \mathrm{mM}$ 3AT. Fresh overnight cultures of KAY641 (wild-type, black symbols) and KAY640 (styl $\Delta$, gray symbols) were inoculated into $\sim 3 \mathrm{ml}$ liquid EMM+Ade medium with $40 \mathrm{mM}$ NAC, $20 \mathrm{mM}$ histidine, and $10 \mathrm{mM}$ 3AT, as indicated. The cultures were started at $\mathrm{A}_{600} \sim 0.3$ with constant agitation at $30^{\circ} \mathrm{C}$, and the aliquots were periodically removed to measure the titer by spotting onto the YES agar plates, which were incubated at $30^{\circ} \mathrm{C}$ for 2 days, and photographed. Colonies formed on each spot was counted to determine the viability, as presented by colony forming units (CFU) per $\mathrm{A}_{600}$. If two or more serially diluted spots contained well-dispersed colonies, the CFU per $\mathrm{A}_{600}$ values obtained from each spot were averaged to determine the viability value for that condition. Three independent viability assays were performed. (B) Graphs show viability (CFU per $\mathrm{A}_{600}$ unit culture) of wild-type (panel 1) and styl $\Delta$ (panel 2) cells exposed to starvation for the times indicated. Bars indicate $\mathrm{SD}(\mathrm{n}=3$, except a single experiment was done with the control 3AT+His treatment). (C) Effect of 3AT and NAC on cell size. Photographs show the wild-type and sty $1 \Delta$ cells under the designated growth condition, with bars indicating $10 \mu \mathrm{m}$. Portions of these cell cultures were withdrawn at indicated times (see legends to the right) and observed under a microscope after fixing with formaldehyde. The graph indicates the average sizes of 20 different cells in $\mathrm{mm}$, which were measured with ImageJ software. The bars in the graph indicate the SD. 




$110^{-1} 10^{-2} 110^{-1} 10^{-2} 110^{-1} 10^{-2} 110^{-1} 10^{-2}$
B

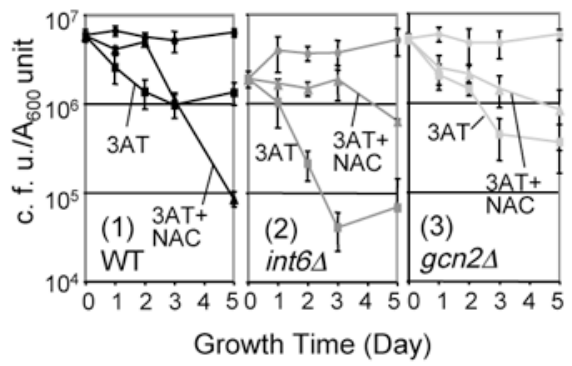

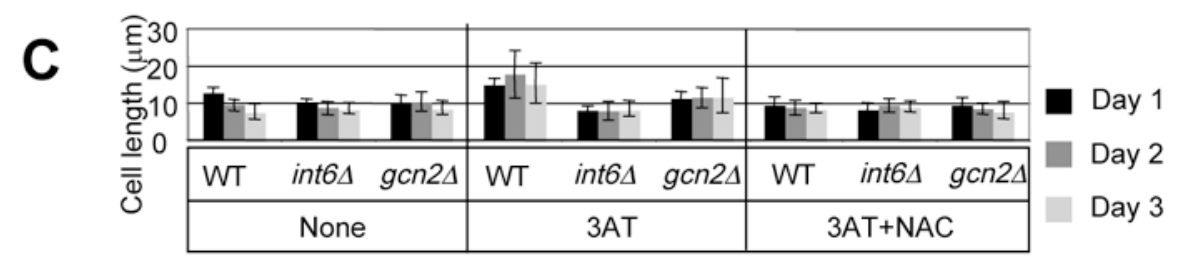

Fig. 4. Int6/eIF3e and Gen2 promote viability during histidine starvation (A-B) Viability assays in the presence of $30 \mathrm{mM}$ 3AT. KAY641 (WT, black symbols, panel 1), KAY647 (int6 $\Delta$, gray symbols, panel 2) and KAY406 ( $g \mathrm{cn} 2 \Delta$, light gray symbols, panel 3) were grown exponentially with $120 \mathrm{mM} \mathrm{NAC}$ and $30 \mathrm{mM} 3 \mathrm{AT}$, as indicated, and assayed for viability, all as in Figs. 3A and B. (B) The time course of cell viability ( $n=3)$ was presented as in Fig. 3B. (C) Effect on cell size. Cultures of the cells used in (A) and (B) were withdrawn at the indicated day and measured for the cell sizes, as in Fig. 3C. 


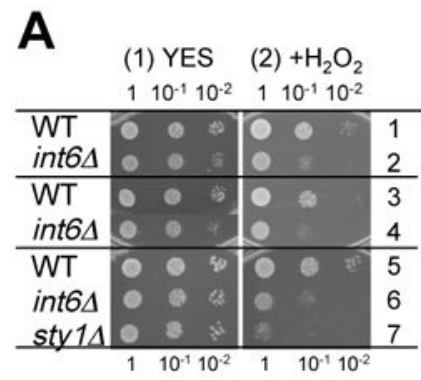

B Viability with $\mathrm{H}_{2} \mathrm{O}_{2}(4 \mathrm{hr})$
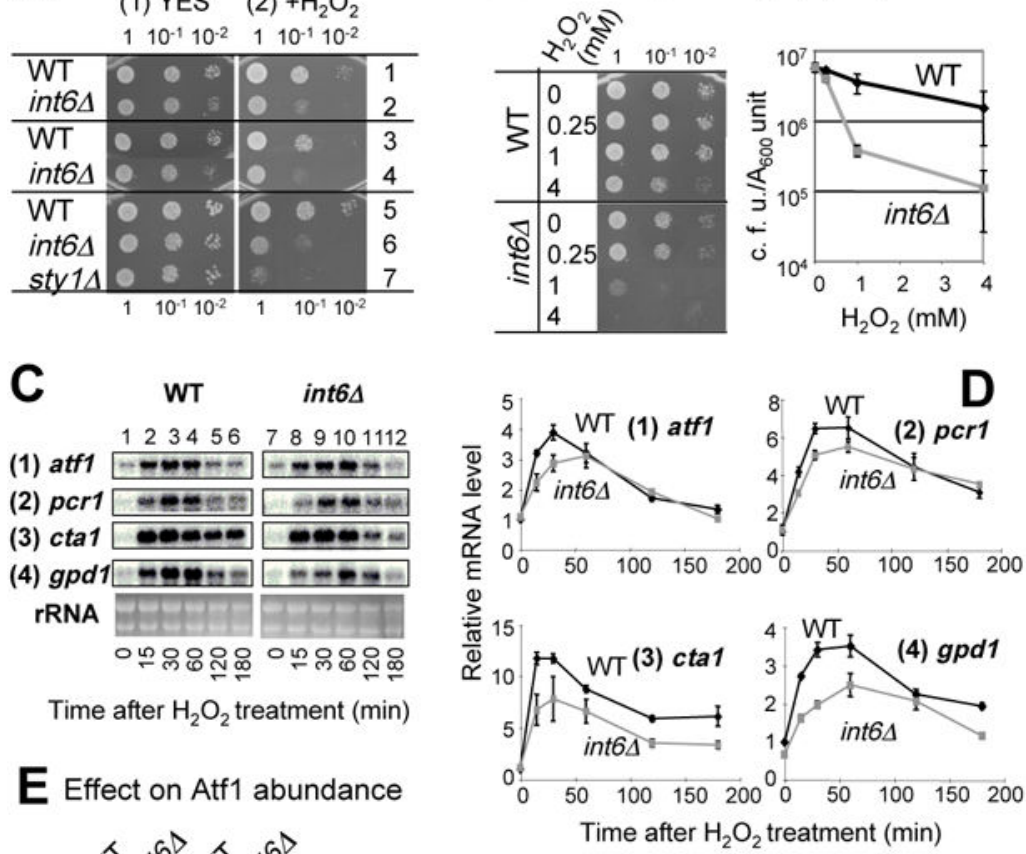

E Effect on Atf1 abundance



Fig. 5. Int6/eIF3e stimulates $\mathrm{H}_{2} \mathrm{O}_{2}$-induced oxidative stress response

(A) Sensitivity test: Cultures of wild type (WT), int6 $\Delta$ or sty $1 \Delta$ strains were diluted and spotted onto YES medium alone (panel 1) or with $1 \mathrm{mM} \mathrm{H}_{2} \mathrm{O}_{2}$ (panel 2), and grown for 2 days. Included in this sensitivity test are strains KAY456 (row 1), KAY508 (row 2), WY764 (row 3), KAY252 (row 4), KAY641 (row 5), KAY647 (row 6), and KAY640 (row 7). (B) Viability test: Strains KAY456 (WT) and KAY508 (int6 $\Delta$ ) were grown to $\mathrm{A}_{600}=0.5$ and then $\mathrm{H}_{2} \mathrm{O}_{2}$ was added at the indicated final concentrations. After incubation for $4 \mathrm{hrs}$, samples were taken, diluted and spotted onto YES agar plates, and the plate was incubated for 2 days. The graph describes the plot of viability (CFU per $\mathrm{A}_{600}$ culture) against exposed $\mathrm{H}_{2} \mathrm{O}_{2}$ dose with bars indicating SD ( $\mathrm{n}=3$ ). (C-D) Effect on CESR transcription: Strains WY764 (WT) and KAY252 (int64) cells were cultured in YES medium with $2 \mathrm{mM} \mathrm{H}_{2} \mathrm{O}_{2}$ for the indicated times in min, and RNA was prepared and analyzed by northern blotting using specific probes for the genes indicated to the left of the panel. The bottom panels show EtBr-stained rRNA, which were included as loading controls. Graphs in (D) show the intensity of the transcript bands shown in (C), compared to the value for wild type at time 0 of $\mathrm{H}_{2} \mathrm{O}_{2}$ treatment. Graphs present the average from two independent experiments. (E) WY764 (WT) and KAY252 (int64) were grown to an exponential phase in YES medium and analyzed by immunoblotting using affinity-purified anti-Atf1 ${ }^{15}$ and anti-tubulin (Sigma) antibodies, as indicated. The graph indicates the levels of Atf1 and Tubulin proteins 
(columns 1-4), averaged from 2 independent experiments, and atf1 mRNA (columns 5-6, average from $n=4$ ) in wild-type vs. int $6 \Delta$ cells, with bars indicating SD. 



Fig. 6. Int6/eIF3e, but not eIF3h, is involved in regulation of atf $^{+}$expression (A) Complementation assay. Wild-type (WT, KAY586) or int6 (KAY587) transformed with pREP41X (Vec), pREP41X-atfl $\left(\right.$ atfl $\left.^{+}\right){ }^{15}$, or pREP-int6 $\left(\text { int } 6^{+}\right)^{23}$ were spotted on EMM-C-his-leu medium alone (panel 1) or with 4 mM 3AT (panel 2), and grown for 4 or 6 days, respectively. (B-C) 3AT sensitivity and total protein synthesis of WT (KAY641), int6D (KAY647) and eif3hs mutant (KAY649). In (B), cells were grown exponentially in the EMM medium, cultured with ${ }^{35} \mathrm{~S}$-Met for $20 \mathrm{~min}$, and cells were collected and protein lysates prepared. $5 \mathrm{mg}$ total proteins were resolved by SDS-PAGE, stained by Coomassie blue (lanes 1-3; M, size standards) and analyzed by the STORM phosphorimager (lanes 4-6). In (C), the 3AT sensitivity was assayed on plates containing EMM-C-his medium alone (panel 1) or supplemented with $5 \mathrm{mM} 3 \mathrm{AT}$ (panel 2) and the plates were incubated for 4 and 6 days, respectively. Because int $6 \Delta$ and eif $3 h \Delta$ mutants grew slowly on the minimal agar plate, but less so on the complete agar plate, we used a complete defined medium EMM-C ${ }^{12}$. 

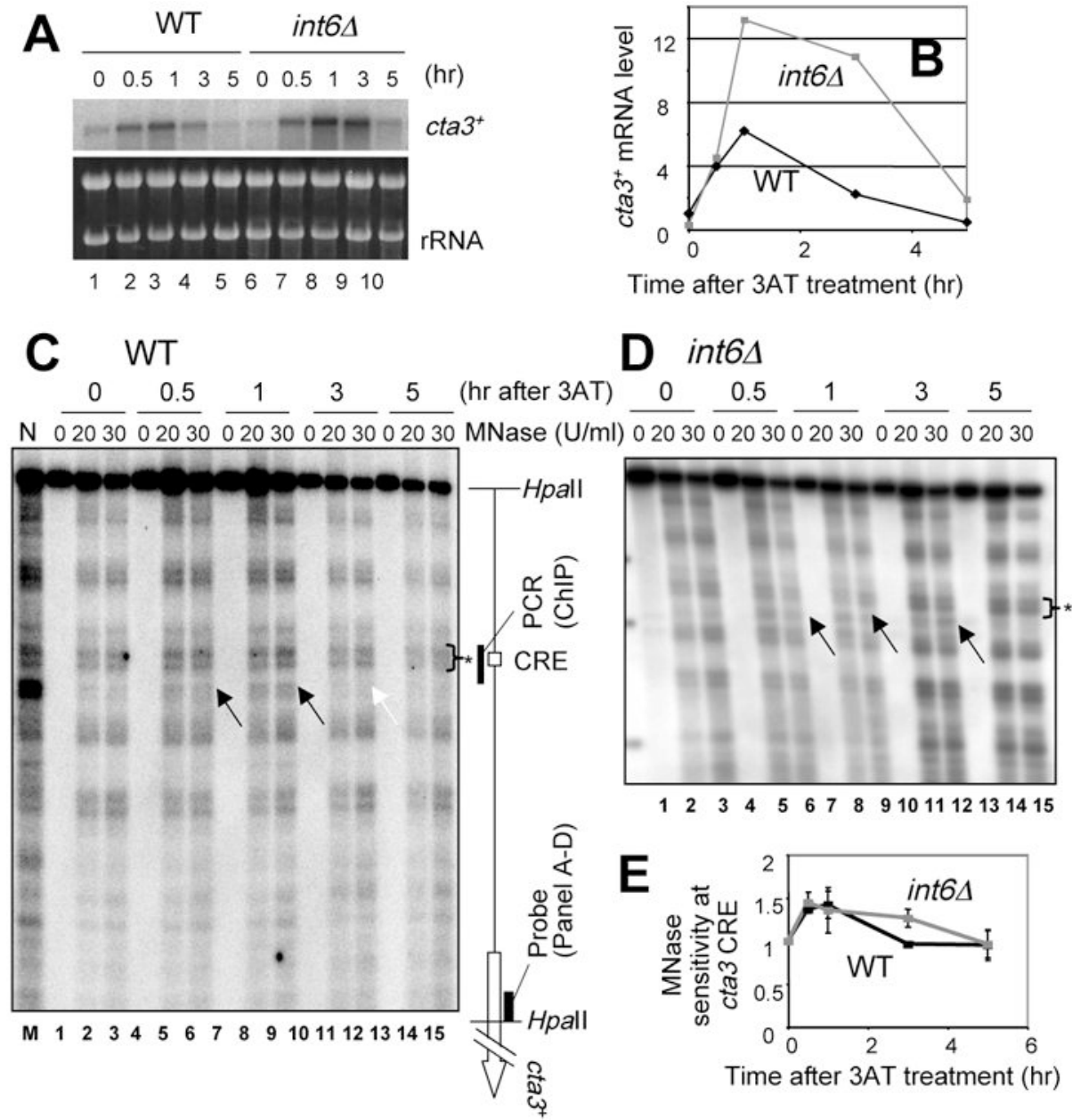

Fig. 7. Direct effect of int6 $\Delta$ on Atf1 activity at its binding site upstream of cta3 $^{+}$ (A-B) Effect of int6 $\Delta$ on 3AT-induced cta $^{+}$mRNA levels. Strains WY764 (WT) and KAY252 (int6 6 ) were grown in the presence of 3AT, withdrawn at the indicated times, and analyzed by northern blotting using a ${ }^{32} \mathrm{P}-c t a 3$ probe as described in Fig. 1.

Autoradiography generated from the northern analysis is illustrated in the top panel (and EtBr staining of rRNA was included as a loading control - bottom panel). Graph in (B) presents the mRNA levels relative to wild-type at time 0. (C-D) Changes in the nucleosome structure at $\mathrm{cta}^{+} \mathrm{CRE}$. Crude chromatin fractions from wild-type (C) and int6 $\Delta$ (D) cells treated with $3 \mathrm{AT}$ for the indicated times were partially digested with MNase at the concentrations listed at the top of the panel. DNA was prepared and and analyzed by Southern blotting, as described in the Experimental Procedures. Black arrows indicate MNase cleavage sites enhanced by 3AT treatment. The White arrow indicates the cleavage site, which disappeared in wild-type DNA after $3 \mathrm{hrs}$ of treatment. The schematic to the right of (C) describes the location of the CRE, the DNA fragments mentioned, and cta $^{+}$ ORF. N, naked DNA treated with MNase. (E) The graph indicates the time course of the intensity of MNase cleavage at the cta3 CRE (arrows in C-D), relative to that of the unchanged cleavage site (asterisks in C-D) in wild-type (black symbols) and int $6 \Delta$ (gray 
symbols) cells. The intensity of cleavage was averaged from lanes with 20 and $30 \mathrm{U} / \mathrm{ml}$ MNase; bars indicate the SD from two independent measurements. 

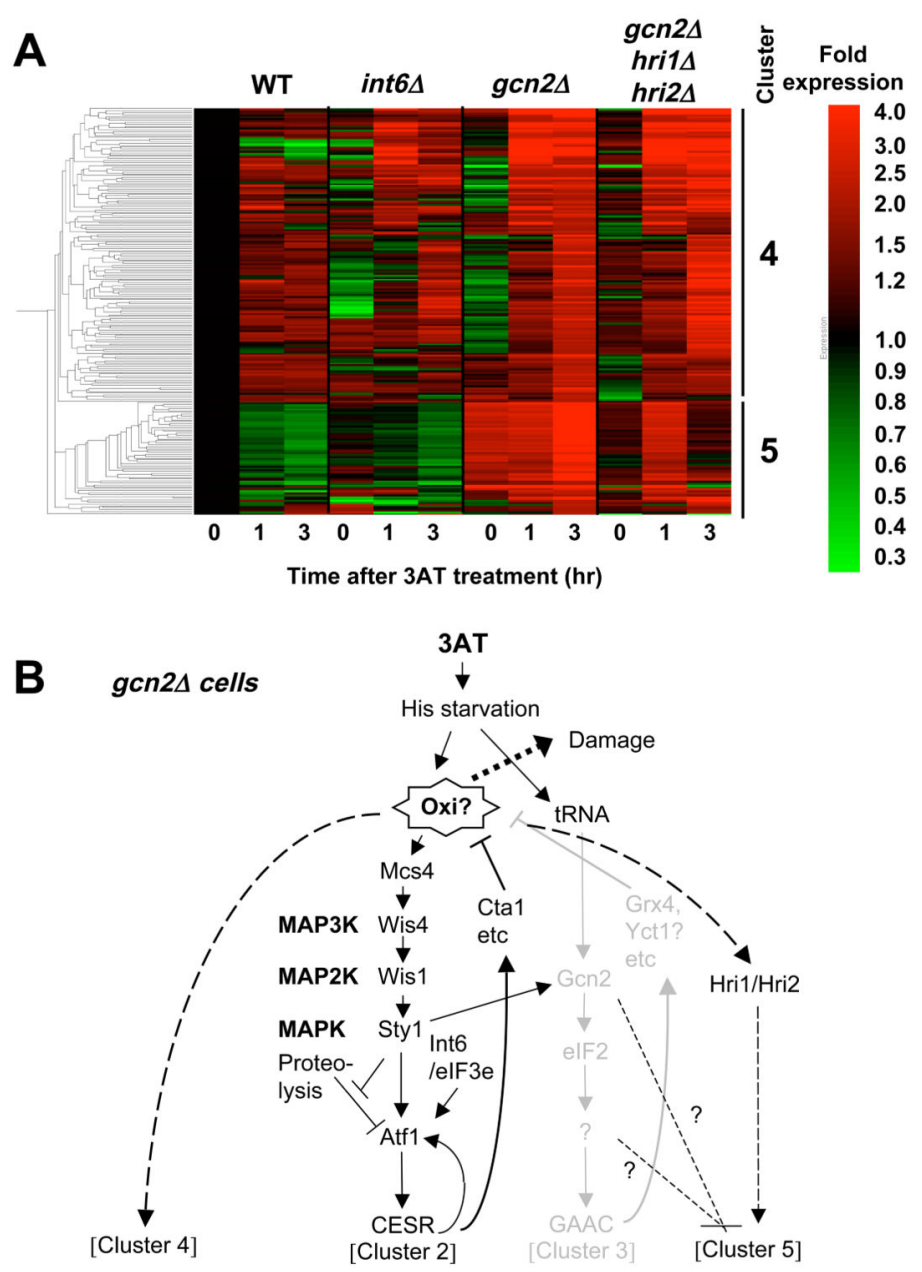

Fig. 8. Genes induced by $3 \mathrm{AT}$ specifically in the absence of $\operatorname{gcn}^{+}$

(A) Clustering of 217 genes induced $<2$-fold in wild-type and $>2$-fold by $30 \mathrm{mM} 3 \mathrm{AT}$ in gcn $2 \Delta$ cells ${ }^{12}$, with the level of expression presented by the red/green scale bar to the right. Each column represents expression level of the genes in yeast carrying mutations indicated across the top after 3AT treatment for the time shown on the bottom. Bars and numbers to the right indicate the gene cluster identified. (B) Model of gene regulation within $g c n 2 \Delta$ cells. Black and gray drawings indicate the pathways proposed to operate or shut down, respectively, in the cells. The model states that the absence of Gcn2 generates oxidative damage (Oxi?), which in turn induces clusters 4 and 5, with the latter repressed by $g c n 2^{+}$ and stimulated by $h r i 1^{+} / h_{r i 2}{ }^{+}$. 

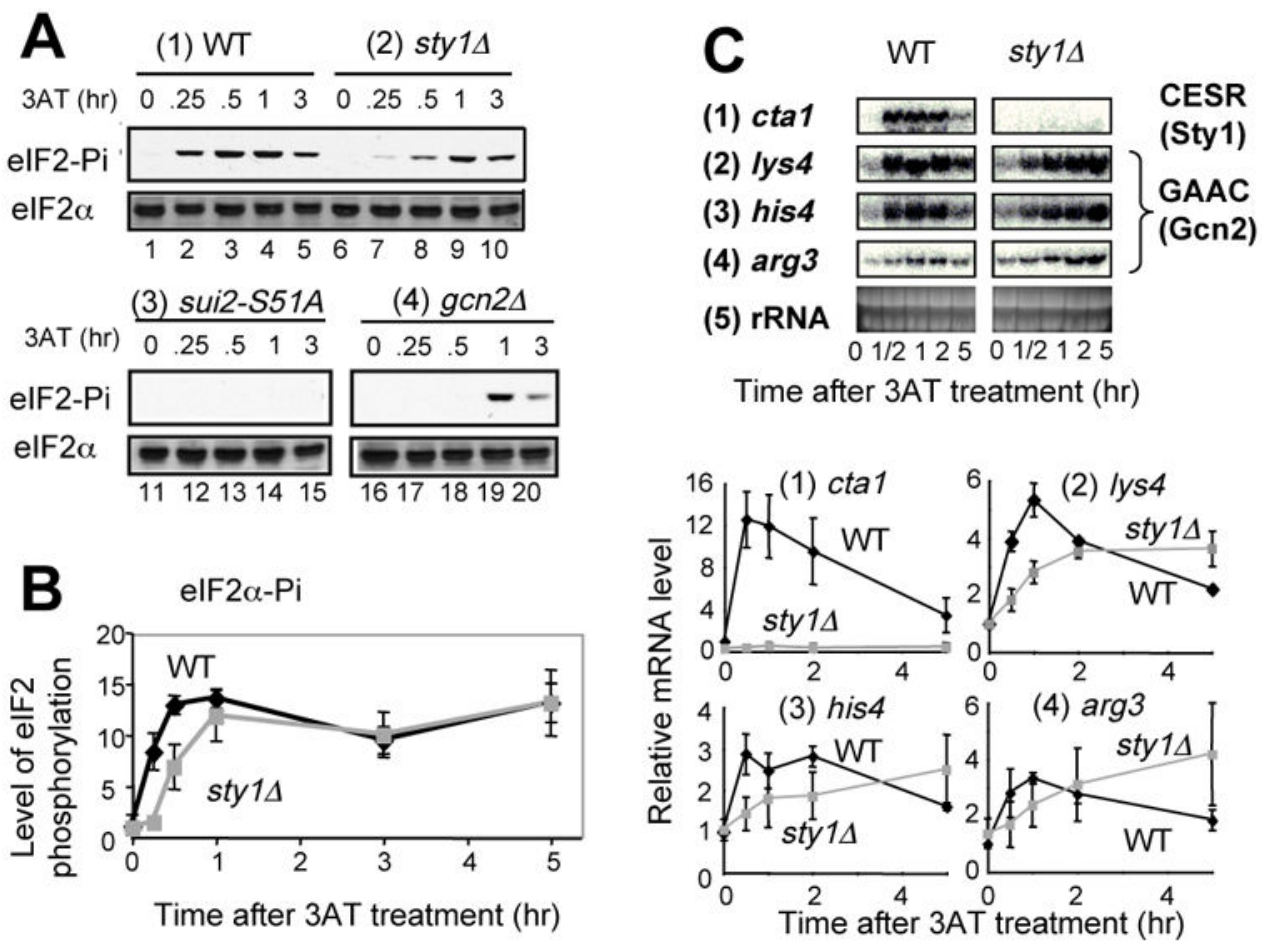

Time after $3 \mathrm{AT}$ treatment $(\mathrm{hr})$

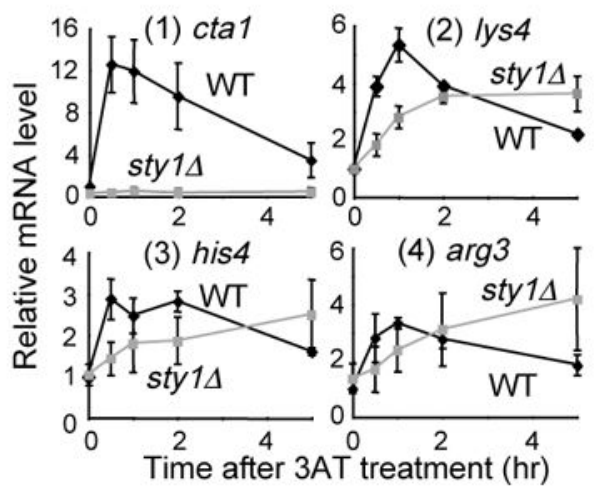

Fig. 9. Sty1 MAPK stimulates Gcn2 phosphorylation of eIF2 $a$

(A) eIF2 phosphorylation: Strains KAY641 (panel 1), KAY640 (panel 2), JP436 (panel 3), and KAY406 (panel 4) were grown in EMM-C-his to an early exponential phase and then 30 mM 3AT was added. Cells were harvested, and protein lysates were prepared and analyzed immunoblotting with anti-phospho eIF2a (top panel) or total eIF2a (bottom panel) antibodies, as described ${ }^{9}$. (B) The graph shows the relative levels of phospho-eIF2a, normalized for total eIF2a levels in the wild-type (black symbols) or sty $1 \Delta$ (gray symbols) cells used in (A). The values are compared to the ratio calculated for wild-type at time 0 . Bars indicate the SD ( $\mathrm{n}=3$ or more). (C) 3AT-induced transcript level changes were examined in strain KAY641 (wild-type) and KAY640 (sty1 $\Delta$ ) for the genes indicated to the left, as described in Fig. 1. 
Table 1

Effect of eif $3 h \Delta$ and int6 $\Delta$ on total protein synthesis and growth rate

\begin{tabular}{|c|c|c|c|}
\hline Strain & Genotype & Total protein synthesis $(\%)^{a}$ & Doubling time $(\min )^{b}$ \\
\hline KAY641 & Wild-type & (100) & $156 \pm 4$ \\
\hline KAY647 & int6s & $18 \pm 1$ & $207 \pm 35$ \\
\hline KAY649 & eif $3 h \Delta$ & $29 \pm 5$ & $187 \pm 23$ \\
\hline
\end{tabular}

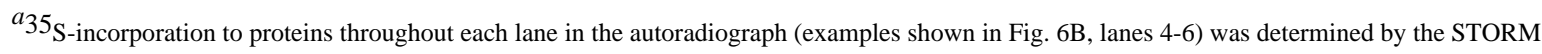
phosphorimager and compared to the value for wild-type (parenthesis). Average of 3 independent experiments.

$b$

Doubling time of each strain was measured in the liquid EMM medium at $30^{\circ} \mathrm{C}$. Average of 4 independent experiments.
} 
Table 2

3AT-induced genes that are dependent on Gcn2 (cluster 3 in Ref ${ }^{12}$ ) and potentially involved in oxidative stress response

\begin{tabular}{|c|c|c|c|c|}
\hline Gene & Systematic Name & $\begin{array}{l}\text { Fold up in } \\
\text { wild-type cells } a\end{array}$ & $\begin{array}{l}\text { Fold up in } \\
\operatorname{gcn} 2 \Delta \text { cells }^{b}\end{array}$ & Description $c$ \\
\hline \multicolumn{5}{|c|}{ DNA repair genes } \\
\hline $\operatorname{grx4}$ & SPAPB2B4.02 & 2.9 & 1.3 & Nuclear glutaredoxin essential for viability \\
\hline C1F12.06c & SPAC1F12.06c & 2.7 & 1.0 & DNA repair endonuclease V (predicted) \\
\hline $\mathrm{C} 18.09 \mathrm{c}$ & $\mathrm{SPCC} 18.09 \mathrm{c}$ & 3.0 & 1.2 & human aprataxin homolog \\
\hline \multicolumn{5}{|c|}{ Cysteine transport } \\
\hline$y c t 1$ & SPCPB1C11.03 & 4.2 & 0.3 & Cysteine transporter (predicted) \\
\hline \multicolumn{5}{|c|}{ Mitochondrial genes } \\
\hline$m m f 1$ & $\mathrm{SPBC} 2 \mathrm{G} 2.04 \mathrm{c}$ & 3.9 & 0.8 & $\begin{array}{l}\text { YjgF family protein similar to } S \text {. cerevisiae } \mathrm{Mmf} 1 \mathrm{p} \text {, which is } \\
\text { involved in mitochondrial DNA stability }\end{array}$ \\
\hline gorl & $\mathrm{SPBC} 1773.17 \mathrm{c}$ & 2.5 & 0.5 & glyoxylate reductase (predicted) \\
\hline atml & SPAC15A10.01 & 4.7 & 0.9 & $\begin{array}{l}\text { mitochondrial inner membrane component, } \mathrm{ABC} \text { family iron } \\
\text { transporter (predicted) }\end{array}$ \\
\hline C3G6.05 & SPAC3G6.05 & 3.2 & 1.2 & $\begin{array}{l}\text { Mvp17/PMP22 family protein } 1 \text {, with a mitochondrial } \\
\text { localization signal }\end{array}$ \\
\hline $\mathrm{C} 1235.11$ & SPCC1235.11 & 2.0 & 0.9 & mitochondrial protein, human BRP44L ortholog \\
\hline $\mathrm{C} 1259.09 \mathrm{c}$ & SPCC $1259.09 \mathrm{c}$ & 2.7 & 0.9 & $\begin{array}{l}\text { Probable pyruvate dehydrogenase protein } \times \text { component, } \\
\text { mitochondrial }\end{array}$ \\
\hline \multicolumn{5}{|c|}{ Homocysteine synthesis } \\
\hline str3 & SPCC11E10.01 & 3.0 & 1.2 & cystathionine $\beta$-lyase (predicted) \\
\hline
\end{tabular}

${ }^{a, b}$ Fold increase in mRNA abundance after $3 \mathrm{hrs}$ of $3 \mathrm{AT}$ treatment, compared to the value in wild-type at time 0.

${ }^{c}$ Based on Gene Ontology (GO) database, with relevant information added from S. pombe Gene Database, 


\section{Table 3}

\section{Strains used in this study}

\begin{tabular}{|c|c|}
\hline Strains & Genotype (Reference if constructed previously) \\
\hline \multicolumn{2}{|c|}{ SP223 derivatives } \\
\hline WY764 & h- ade6-M216 leu1-32: :leu1 ${ }^{+}$ura4-D18: :ura4 ${ }^{+}(1)$ \\
\hline KAY252 & 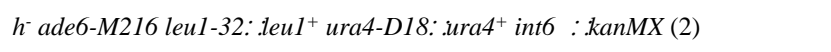 \\
\hline KAY406 & $h^{-}$ade6-M216 leu1-32: :leu1 ${ }^{+}\left\langle p J K 148>\right.$ ura4-D18 gcn $2 \Delta: u_{\text {ura }} 4^{+}(2)$ \\
\hline \multicolumn{2}{|c|}{ JY878 derivatives } \\
\hline KAY456 & $h^{90}$ ade6-M216 leu1-32: :leu1 ${ }^{+}<p J K 148>$ ura4-D18: :ura4 ${ }^{+}(2)$ \\
\hline KAY508 & $h^{90}$ ade6-M216 leu1-32: :leu1 ${ }^{+}\left\langle p J K 148>\right.$ ura4-D18: :ura $4^{+}$int6s: :kanMX (2) \\
\hline \multicolumn{2}{|c|}{ JY879 derivatives } \\
\hline KAY586 & $h^{90}$ ade6-M210 leu $1-32$ ura4-D18 ura $^{+}$ \\
\hline KAY587 & $h^{90}$ ade6-M210 leu1-32 ura4-D18 ura $^{+}$int6s: :kanMX \\
\hline \multicolumn{2}{|c|}{ PR109 derivatives } \\
\hline KAY 641 & $h^{-}$leu1-32: :leu1 ${ }^{+}<p J K 148>$ ura4-D18: :ura4 ${ }^{+}(2)$ \\
\hline KAY647 & h- leu1-32: :leu1 ${ }^{+}<p J K 148>$ ura4-D18: ura4 $4^{+}$int6s: :kanMX (2) \\
\hline KAY640 & $h^{-}$leu1-32: :leu1 ${ }^{+}<p J K 148>$ ura4-D18 sty14: :ura4 ${ }^{+}(2)$ \\
\hline KAY649 & h-leu1-32: :leu1 ${ }^{+}<p J K 148>$ ura4-D18 eif $3 h \Delta::$ ura $^{+}$ \\
\hline KAY793 & 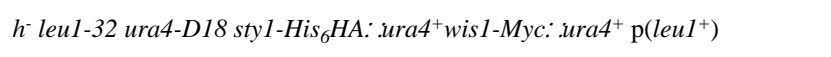 \\
\hline KAY794 & h- leu1-32 ura4-D18 sty1-His ${ }_{6} H A::$ ura $^{+}$mcs4: :ura4 $4^{+} \mathrm{p}\left(\right.$ leu1 $\left.1^{+}\right)$ \\
\hline \multicolumn{2}{|c|}{ Miscellaneous } \\
\hline JP3 & $h^{-}(3)$ \\
\hline JP260 & $h^{+}$wisl: :kanMX $(3)$ \\
\hline JP436 & $h^{+}$ade6-M210 ura4-D18 sui2-S51A: :ura4 ${ }^{+}(4)$ \\
\hline KAY852 & $h^{90}$ ade6-M210 leu1-32 ura4-D18 his7-366 wis4: :ura $4^{+} \mathrm{p}\left(\right.$ leu1 $\left.1^{+}\right) \mathrm{p}\left(\right.$ his $\left.7^{+}\right)$ \\
\hline
\end{tabular}

References: 1 . Ref ${ }^{10}$

2. $\operatorname{Ref}^{12}$

3. $\operatorname{Ref}^{52}$

4. $\operatorname{Ref}^{33}$ 
Table 4

List of oligodeoxyribonucleotides used in this study

\begin{tabular}{|c|c|c|c|}
\hline \multicolumn{4}{|c|}{ The following primers were designed to create and confirm the strains deleted for eif $3 h^{+}$} \\
\hline & Name & Nucleotide sequences $\left(5^{\prime}\right.$ to $\left.3^{\prime}\right)$ & Gene \\
\hline 1 & eIF3h-FW & $\begin{array}{l}\text { TAGAAAAGGTTTAATAAAACTGGTAGG } \\
\text { CTCCTCTATTCTATAACTTGTAATCGCC } \\
\text { GACAGCCATGGCTTTAAAAAGTTGCCG } \\
\text { GATCCCCGGGTAATTAA } \\
\text { TTAAGTAGATCCTTTATTTAAATGCTAC } \\
\text { GAGGTATAACTAGTGAGAGTGAAGAAGA } \\
\text { ATGCTCCATTTTTTATAAACAAAGAATTC }\end{array}$ & eif3h \\
\hline 2 & eIF3h-RV & GAGCTCGTTTAAAC & eif3h \\
\hline 3 & eIF3h-up & GAGCTTAAGGCCGAGAAAAC & $e i f 3 h$ \\
\hline 4 & eIF3h-down & TATGCTGTATCAAGAAAACC & eif $3 h$ \\
\hline 5 & ura4-midF & GTGTGTACTTTGAAAGTCTAGCTTTA & ura4 \\
\hline 6 & ura4-midR & CCTTGTATAATACCCTCGCC & ura4 \\
\hline \multicolumn{4}{|c|}{ The following primers were designed by the Bähler group in their microarray studies ${ }^{61}$} \\
\hline 7 & 2-A11_C418.01c_his4_F & TAGAGAACTCCTTTGGCGGA & his4 \\
\hline 8 & 2-A11_C418.01c_his4_R & CAACTTCGACAGCAGGATGA & his4 \\
\hline 9 & 20-G9_arg3_F & TCTCCAGGCGTTAGCAGATT & $\arg 3$ \\
\hline 10 & 20-G9_arg3_R & TGCATGAATTTGCAGCTAGG & $\arg 3$ \\
\hline 11 & 2-E7_C1105.02c_lys4_F & CAACCGTGTTGGTATTGCTG & lys 4 \\
\hline 12 & 2-E7_C1105.02c_lys4_R & GCGACAAGGTTTTCAAGCTC & lys 4 \\
\hline 13 & 53-F9_atf1 mts1 sss1 gad7_F & ACCCCTACTGGAGCTGGATT & atfl \\
\hline 14 & 53-F9_atf1 mts1 sss1 gad7_R & TACCTGTAACAGCTTGGGGG & atfl \\
\hline 15 & 27-H10_cr1 mts2 F & CGCTTCTAAATTTCGCCAGA & pcrl \\
\hline 16 & 27-H10_cr1 mts2_R & GGTGTTGATTTGGAGGGAGA & pcrl \\
\hline 17 & 33-G9_gpd1_F & GGTGTAGTTGGCTCCGGTAA & gpdl \\
\hline 18 & 33-G9_gpd1_R & TCTCACAGAATTGCTCACGG & gpdl \\
\hline 19 & 12-F1_cta1_F & TTCGTGATCCCGCTAAATTC & ctal \\
\hline 20 & 12-F1_cta1_R & AAGGTAAAGCGTCCAACCCT & ctal \\
\hline \multicolumn{4}{|c|}{ The following primers were designed by the group of K. Ohta (see Fig. 7C) } \\
\hline 21 & cta3 ORF-5' & CGAACATTGGCTTCTCC & $c t a 3$ \\
\hline 22 & cta3 ORF-3' & GGTTGCGTAACAAATTCC & $c t a 3$ \\
\hline 23 & cta3 CRE-5' & TAACAACACTCCGCCATTCG & $c t a 3$ \\
\hline 24 & cta3 CRE-3' & TGACTCCGACATTGATTTCCT & $c t a 3$ \\
\hline
\end{tabular}

